\title{
Impact of Apolipoprotein E Genotype Variation on Means, Variances, and Correlations of Plasma Lipid, Lipoprotein, and Apolipoprotein Traits in Octogenarians
}

\author{
Martha B. Haviland, Suzanne Lussier-Cacan, Jean Davignon, and Charles F. Sing \\ Department of Human Genetics, University of Michigan, Ann Arbor, Michigan (M.B.H., C.F.S.), and Hyperlipidemia \\ and Atherosclerosis Research Group, Clinical Research Institute of Montreal, Montreal, Canada (S.L.-C., J.D.)
}

The impact of apolipoprotein (apo) $\mathbf{E}$ genotype variation on means, variances and correlations between plasma lipid traits was studied in male and female octogenarians. Females had significantly higher mean levels of all 10 of the measured plasma lipid traits than males. The subset of concomitants (i.e., age, height, weight, body mass index, glucose and uric acid) that made a statistically significant contribution to interindividual variability was different in males and females for every trait considered. Gender-specific associations between variation in apo $E$ genotype and variation in particular measures of lipid metabolism, adjusted for concomitant variation, were observed: in females there were no statistically significant associations while in males the means of the three common apo $E$ genotypes were significantly different for adjusted measures of total cholesterol, low density lipoprotein cholesterol and low density lipoprotein-apo B. The common apo $\mathbf{E}$ genotypes were heterogeneous with respect to intragenotypic variance for adjusted logtransformed triglyceride levels in females only. Finally, the three common apo $\mathbf{E}$ genotypes were heterogeneous with respect to the correlation between traits, adjusted for concomitant variation, and gender influenced the manner in which the genotypes differed for specific correlations. This study documents that variation in the apo $E$ gene has a significant impact on means, variances

Received for publication September 9, 1994; revision received April 7, 1995.

Address reprint requests to Martha B. Haviland, Ph.D., Department of Human Genetics, M4708 Medical Science Bldg. II, University of Michigan Medical School, Ann Arbor, MI 481090618. and correlations of plasma lipid traits in octogenarians, but the effects are context-, that is, gender- and age-, dependent.

(C) 1995 Wiley-Liss, Inc.

KEY WORDS: apolipoprotein $E$, means, variances, correlations, octogenarians, aging, plasma lipid traits, gender

\section{INTRODUCTION}

The common polymorphic alleles of the gene coding for apolipoprotein (apo) $\mathrm{E}, \epsilon 2, \epsilon 3$ and $\epsilon 4$, have been shown to be associated with variation in plasma lipoprotein levels in samples of both healthy [Sing and Davignon, 1985; Boerwinkle et al., 1987; Kaprio et al., 1991; Reilly et al., 1991; Xhignesse et al., 1991; Davignon, 1993] and diseased individuals (for a review see Davignon et al., 1988b; Davignon, 1993). The $\epsilon 4$ allele is associated with increased levels of low density lipoprotein cholesterol (LDL-C) and apo B, and thus is hypothesized to be associated with increased risk of coronary artery disease (CAD). This hypothesis is supported by cross-sectional studies demonstrating an association between the $\epsilon 4$ allele and presence of CAD [Cumming and Robertson, 1984; Kuusi et al., 1989; Pedro-Botet et al., 1992; Eichner et al., 1993] and by a prospective study in which the $€ 4$ allele was predictive of CAD mortality [Stengård et al., 1995]. There is evidence that the presence of the $\epsilon 4$ allele may be a risk factor for CAD even in the absence of elevated plasma LDL-C [Hixson et al., 1991]. The $\epsilon 2$ allele is associated with decreased levels of LDL-C, a potentially antiatherogenic effect. It may also be associated with increased concentrations of triglyceride-rich lipoproteins and thus could, in some circumstances, favor the development of atherosclerosis. These findings have led to the hypothesis that variation in the apo $\mathrm{E}$ gene may play an important role in determining interindividual variation in risk of atherosclerosis in general and of 
CAD in particular [Davignon et al., 1988b; Davignon, 1991, 1993].

This study is one in a series of studies examining the effects of apo $\mathrm{E}$ genotype variation on the phenotypic distributions of measures of lipid metabolism in octogenarians. A previous study, using the same sample analyzed here, demonstrated that the relative frequency of the $\epsilon 4$ allele was decreased in octogenarians as compared to normal subjects of a younger age group [Davignon et al., 1988a, 1989]. Based on the fact that cardiovascular diseases and, specifically $\mathrm{CAD}$, constitute, in a progressive fashion, the principal cause of mortality with aging, this finding is consistent with the hypothesis that genetic variation in apo $\mathrm{E}$ influences variation in risk of CAD. In these previous studies, gender differences in the apo $\mathrm{E}$ allele frequencies and in the plasma lipid levels and clinical phenotypes of the octogenarians were observed [Davignon et al., 1988a, 1989]. The decrease in the $\epsilon 4$ allele frequency was statistically significant in females only and an enrichment in the $\epsilon 2$ allele was present in males but was not statistically significant. Also, female octogenarians had a higher frequency of hyperlipidemia, hypertension, and $\mathrm{CAD}$ and lower frequency of smoking and exercise than male octogenarians.

To further study the impact of variation in the apo $\mathrm{E}$ gene on the phenotypic distributions of measures of lipid metabolism in octogenarians, the effects of apo $E$ genotype variation on means, variances and correlations between plasma lipid, lipoprotein and apolipoprotein traits were estimated, after adjustment for concomitants, separately in males and females. This study suggests that variation in the apo $\mathrm{E}$ gene is involved in the modulation of lipid metabolism differently in male and female octogenarians. Our findings are discussed in the context of previously published work in samples of younger individuals to draw conclusions about the effects of aging on the impact of variation in the apo $\mathrm{E}$ gene on the phenotypic distributions of measures of lipid metabolism.

\section{MATERIALS AND METHODS Sample}

Octogenarian subjects were recruited from 6 homes for the aged and one Veterans Hospital. As described previously [Davignon et al., 1988a, 1989], the subjects were selected to be ambulatory and autonomous, at least 80 years old, capable of answering a questionnaire and willing to submit to a short physical examination and the drawing of blood. Exclusion criteria included subjects with chronic debilitating disease (e.g., cancer, Parkinson's disease, etc.), mental illness, alcoholism, untreated hypothyroidism, or within the previous three months, major surgery, weight change $( \pm 10 \%)$ or a myocardial infarction. The sample analyzed here consisted of 236 unrelated octogenarians (118 females and 118 males).

\section{Laboratory Methods}

Laboratory methods are described in detail elsewhere [Davignon et al., 1988a, 1989]. Briefly, blood samples were obtained after a 12 hour fast and sepa- rated for automatic enzymatic determination of plasma total cholesterol (TC) [Allain et al., 1974], triglycerides (TG) [Sampson et al., 1975], glucose [Richterich and Dauwalder, 1971] and uric acid [Kageyama, 1971]. Plasma lipoproteins were separated according to the Lipid Research Clinics protocol [Lipid Research Clinics Program, 1974]. Plasma apo B, LDL-apo B (LDL-B) and very low density lipoprotein-apo B (VLDL-B) concentrations were determined using the method of Reardon et al. [1981] with the modification of Rosseneu et al. [1981]. The subfractions of plasma high density lipoprotein cholesterol, HDL2-C and HDL3-C, were determined after precipitation of HDL2 [Gidez et al., 1982]. Apo E phenotyping was done on the washed VLDL fraction by unidimensional isoelectric focusing on polyacrylamide gel [Bouthillier et al., 1983]. Six apo E genotypes, $\epsilon 2 / 2, \epsilon 3 / 2, \epsilon 3 / 3, \epsilon 4 / 3, \epsilon 4 / 2$ and $\epsilon 4 / 4$, were inferred from the isoform phenotypes, E2/2, E3/2, E3/3, $\mathrm{E} 4 / 3, \mathrm{E} 4 / 2$ and $\mathrm{E} 4 / 4$, coded by the three polymorphic alleles, $\epsilon 2, \epsilon 3$ and $\epsilon 4$.

\section{Statistical Methods}

All analyses were carried out using the SAS software package [SAS Institute Inc., 1989]. Statistical tests that gave $P$-values less than or equal to 0.05 were considered significant. All analyses were performed separately on males and females. Triglycerides, VLDL-C, VLDL-B and HDL3-C were not normally distributed in males and females, while LDL-C, HDL-C, HDL2-C, apo $B$ and LDL-B were not normally distributed in males only (results not shown). Many of the statistical tests performed here are sensitive to deviations from normality, so the plasma lipid traits were analyzed both transformed with the natural logarithm and untransformed. The untransformed results are presented and those instances in which a deviation from normality affected the inferences drawn are noted.

The means, standard deviations and ranges of the concomitants (i.e., age, height, weight, body mass index (BMI), glucose and uric acid) and measures of lipid metabolism were estimated. Differences between males and females were tested using a t-test for means and a F-statistic for variances. To test whether the observed heterogeneity in the intragenotypic variances among the three common apo E genotypes was statistically significant, Bartlett's test was used [Sokal and Rohlf, 1981].

Multiple linear regression was employed to study interindividual variability associated with concomitants [Neter et al., 1985]. Model fitting was done in two ways. First, we used a stepwise procedure to evaluate which of the concomitants made a statistically significant contribution to interindividual variability in the plasma lipid traits. The inferences made are conditional on the order in which the concomitants were fit. The order selected was: age, height, weight, BMI, glucose and then uric acid. As each concomitant was added to the model, we tested the hypothesis that the concomitant explained a significant fraction of interindividual plasma lipid variability given the other concomitants already present in the model. A concomitant was retained in the model if it significantly explained interindividual variability in at least one plasma lipid 
trait. If a concomitant was retained in the model, the concomitant squared was added to the model and if the squared term was statistically significant in at least one trait it was retained in all models and the cubed term was tested. If the squared term was not significant for any plasma lipid trait, the cubed term was not tested, the squared term was removed from the model, and the analysis progressed to the next concomitant. The cubed and fourth-order terms were tested analogously. The second modelling strategy was to fit a most complete model to remove as much interindividual variability attributable to concomitant variability as possible. The most complete model included age, height, weight, BMI, glucose and uric acid all to the fourth order. All tests of significance about the contribution of concomitants were made using the error sum of squares associated with the most complete model. A few outliers ( 7 females and 8 males) with values greater than 3 standard deviations from the gender-specific mean for one or more concomitant traits were found to have a large impact on the results. All models were fit with and without these outliers in the analysis.

To estimate the association between apo E genotype variability and interindividual variability in adjusted plasma lipid levels, the apo $\mathrm{E}$ genotypes were added to the most complete model described above. Thus, the inferences made about the impact of the apo E genotypes on plasma lipid variability are conditional on the removal of the contribution of concomitants.

After adjusting the plasma lipid levels using the most complete model, the Pearson product moment correlations between the adjusted plasma lipid levels were estimated for each of the common apo $E$ genotypes for each gender. The hypothesis of homogeneity of correlation among these genotypes was tested within each gen- der [Sokal and Rohlf, 1981]. The Pearson product moment correlations and the tests of homogeneity of correlation of the adjusted plasma lipid traits for each of the common apo $\mathrm{E}$ genotypes for each gender are given in Appendices B and C. The results for all correlations, except those involving total cholesterol, total apo B and total HDL-C, are also depicted in Figures 2 and 3. Statistical significance depends both on the size of the correlation and the sample size. For the comparison among the apo E genotypes, each with different sample sizes, the figures show the biologically significant [Hennekens and Buring, 1987] but not always statistically significant correlations. We define biologically significant correlations as those greater than 0.3 or less than -0.3 . The statistical significance levels for all correlations and tests of the hypothesis of homogeneity of correlation are given in Appendices B and $\mathrm{C}$ and will be stated in the text. Those instances in which inferences changed when the plasma lipid traits were $\log _{\mathrm{e}}$-transformed before the adjustment are noted in Appendices $\mathrm{A}-\mathrm{C}$, and the figures depict the $\log _{\mathrm{e}}$-transformed results.

\section{RESULTS}

The means, standard deviations and ranges for the concomitants and measures of plasma lipid metabolism are given in Table I. Males and females were significantly different for means and/or variances for every concomitant except uric acid and diastolic blood pressure. On the average, females were younger, shorter, weighed less and had lower glucose and uric acid levels, but their blood pressure was higher than males. Females also had significantly higher average levels of all of the measures of plasma lipids than males. Finally, females had significantly greater interindividual variation in BMI, HDL3-C, LDL-B and $\log _{\mathrm{e}}$-transformed VLDL-B levels and significantly less interindividual

TABLE I. Descriptive Summary of the Sample

\begin{tabular}{|c|c|c|c|c|c|c|c|c|}
\hline & \multirow{2}{*}{\multicolumn{3}{|c|}{$\begin{array}{c}\text { Females } \\
(\mathrm{n}=118)\end{array}$}} & \multirow{2}{*}{\multicolumn{3}{|c|}{$\begin{array}{c}\text { Males } \\
(\mathrm{n}=118)\end{array}$}} & \multicolumn{2}{|c|}{$P$-Values } \\
\hline & & & & & & & \multirow{2}{*}{$\begin{array}{l}\text { T-test } \\
\text { Means }\end{array}$} & \multirow{2}{*}{$\begin{array}{c}\text { F-test } \\
\text { Variances }\end{array}$} \\
\hline & Mean & S.D. & Range & Mean & S.D. & Range & & \\
\hline \multicolumn{9}{|l|}{ Concomitants } \\
\hline Age (year) & 83.85 & 3.31 & $80.0-100.0$ & 85.62 & 4.82 & $80.0,100.0$ & $<0.01$ & $<0.01$ \\
\hline Height $(\mathrm{cm})$ & 151.12 & 7.91 & $119.0-170.0$ & 166.05 & 7.62 & $136.0,188.0$ & $<0.01$ & 0.68 \\
\hline Weight (kg) & 56.46 & 10.85 & $35.5-95.3$ & 67.41 & 10.76 & $45.5, \quad 99.0$ & $<0.01$ & 0.92 \\
\hline $\mathrm{BMI}\left(\mathrm{kg} / \mathrm{m}^{2}\right)$ & 24.87 & 5.27 & $14.5-41.7$ & 24.43 & 3.41 & $16.3, \quad 37.5$ & 0.44 & $<0.01$ \\
\hline Glucose (mg/dl) & 99.97 & 23.44 & $68.0-212.0$ & 108.46 & 42.80 & $78.0,395.0$ & 0.06 & $<0.01$ \\
\hline Uric acid (mg/dl) & 3.66 & 1.00 & $2.1-8.8$ & 3.84 & 1.00 & $2.3, \quad 8.5$ & 0.16 & 0.98 \\
\hline Systolic BP & 148.85 & 23.91 & $90.0-240.0$ & 141.97 & 20.43 & $95.0,190.0$ & 0.02 & 0.09 \\
\hline Diastolic BP & 72.66 & 13.02 & $40.0-120.0$ & 71.69 & 12.96 & $40.0,120.0$ & 0.56 & 0.96 \\
\hline \multicolumn{9}{|c|}{ Plasma lipid traits (mg/dl) } \\
\hline TG & 143.21 & 70.75 & $48.0-409.0$ & 125.70 & 64.22 & $43.0,392.0$ & 0.05 & 0.30 \\
\hline $\mathrm{TC}$ & 224.62 & 41.99 & $121.0-325.0$ & 190.13 & 38.49 & $100.0,321.0$ & $<0.01$ & 0.35 \\
\hline VLDL-C & 30.94 & 16.11 & $10.0-89.0$ & 26.66 & 15.53 & $7.0,103.0$ & 0.04 & 0.69 \\
\hline LDL-C & 147.75 & 36.07 & $45.0-230.0$ & 123.53 & 33.09 & $47.0,215.0$ & $<0.01$ & 0.35 \\
\hline HDL-C & 45.92 & 11.00 & $23.0-77.0$ & 39.93 & 12.34 & $19.0,89.0$ & $<0.01$ & 0.22 \\
\hline HDL2-C & 21.11 & 8.32 & $6.0-49.0$ & 18.64 & 10.12 & $3.0, \quad 55.0$ & 0.04 & 0.04 \\
\hline HDL3-C & 24.81 & 4.98 & $12.0-39.0$ & 21.30 & 3.98 & $13.0, \quad 34.0$ & $<0.01$ & 0.02 \\
\hline Apo B & 158.14 & 39.14 & $68.0-261.0$ & 128.61 & 35.10 & $55.0,234.0$ & $<0.01$ & 0.24 \\
\hline VLDL-B & 23.13 & 14.19 & $3.0-77.0$ & 17.34 & 15.88 & $1.0,107.0$ & $<0.01$ & $0.22^{b}$ \\
\hline LDL-B & 135.02 & 34.94 & $39.0-224.0$ & 111.33 & 28.36 & $53.0,186.0$ & $<0.01$ & 0.02 \\
\hline
\end{tabular}

\footnotetext{
"When the assumption of equal variances was violated, Satterthwaite's approximation was used.
}

${ }^{b}$ When $\log _{\mathrm{e}}$-transformed, variances significantly heterogeneous $(P \leq 0.01)$. 
variation in age, glucose and HDL2-C levels than males. These results show that there are significant gender differences in the distributions of both concomitants and plasma measures of lipid metabolism in octogenarians.

The results of the stepwise regression to determine which concomitants made a significant contribution to interindividual plasma lipid trait variability are given in Appendix A. Concomitants were statistically significant in the first, second and/or third order. The fourth order term was not statistically significant for any concomitant in any trait. A summary of those concomitants that made a statistically significant contribution to interindividual variation in each plasma lipid trait is given in Figure 1. The regression results can be summarized by recognizing that interindividual variability in each plasma lipid trait was associated with variability in a different set of concomitants. Also, by comparing the upper and lower triangles in Figure 1, differences between the genders are clearly apparent. For every plasma lipid trait studied, the set of statistically significant concomitants was different between males and females.

Table II gives the means and standard deviations of the adjusted plasma lipid levels (adjusted using the most complete model, i.e., age, height, weight, BMI, glucose and uric acid all to the fourth order) by apo $\mathbf{E}$ genotype separately for males and females. In males, all six of the possible apo E genotypes were present in our sample, but in females only the three most common genotypes, $\epsilon 3 / 2, \epsilon 3 / 3$ and $\epsilon 4 / 3$, were present. Table III gives the percentage of interindividual trait variability explained by concomitant variability (using the most complete model), the percentage explained by apo $\mathrm{E}$ genotype variability after removing the contribution of the concomitants, the percentage left unexplained and the total sum of squares. The percent sum of squares attributable to the concomitant variability ranged from $22 \%$ for LDL-B to $44 \%$ for triglycerides in females and from $17 \%$ for HDL3-C to $36 \%$ for HDL2-C in males. Although the percent sum of squares attributable to variability in concomitants was similar in males and females for most traits, the absolute sum of squares attributable to variability in the concomitants, as well as the total sum of squares, was greater in females than in males for all traits except HDL-C and HDL2-C.

As was the case for the regression of plasma lipid traits on concomitants, the fraction of the total interindividual variability in this sample attributable to apo E genotype variability, after considering the concomitants, was also very different in males and females (Table III). In females, apo E genotype variability did not significantly contribute to adjusted interindividual variability in any of the plasma traits considered. Not only was the percent sum of squares attributable to apo $\mathrm{E}$ genotype variability small in females, but also the absolute sum of squares attributable to apo $\mathrm{E}$ genotype variability was smaller than that in males even though the total sum of squares was greater in females for most of the traits. In all males, apo $\mathrm{E}$ genotype variability had a significant effect on interindividual variability in every lipid trait except HDL-C (both fractions). When the analysis was restricted to males carrying only the three most common apo $\mathrm{E}$ genotypes, $\epsilon 3 / 2, \epsilon 3 / 3$ and $\epsilon 4 / 3$, concomitants explained about the same amount of plasma lipid trait variability. In this reduced data set, variability in apo $\mathrm{E}$ genotype had a statistically significant effect on interindividual variability in adjusted measures of LDL metabolism only. The three common apo E genotypes explained $9.7 \%$ of the total sum of squares for adjusted total cholesterol, $11.2 \%$ for adjusted LDL-C, $9.5 \%$ for adjusted apo B, and

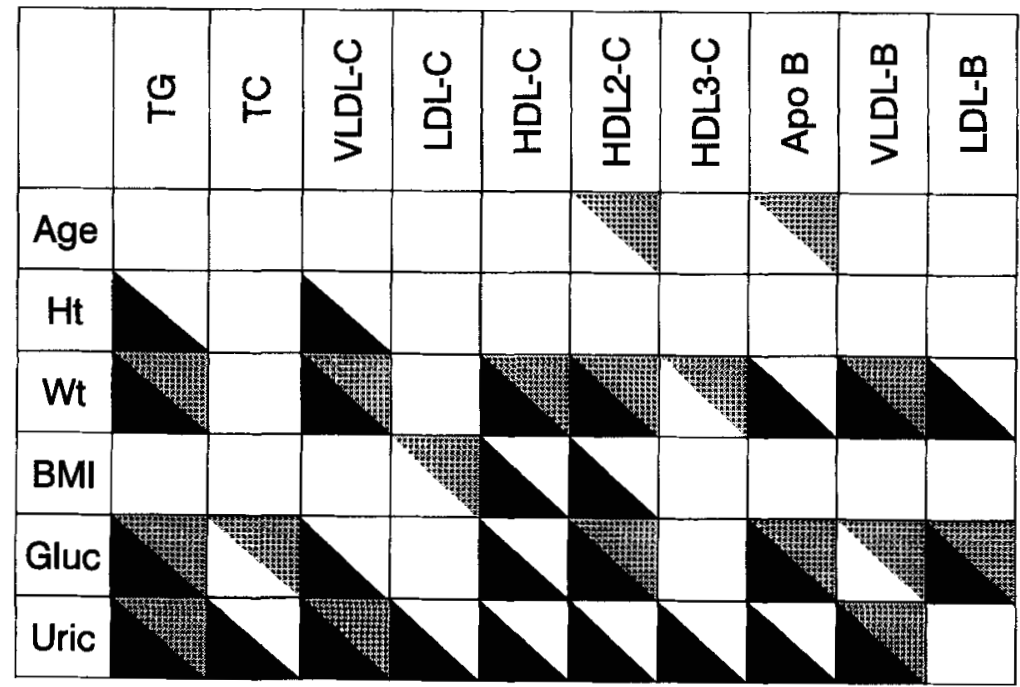

Fig. 1. Concomitant variables (in the first, second and/or third order) in females (upper stippled triangle) and in males (lower solid triangle) that significantly contributed to plasma lipid variability. Concomitants that were statistically significant in all analyses, only when the outliers were removed from the analysis, or only when the dependent variable was $\log _{\mathrm{e}}$-transformed, are included in the figure. Those concomitants that were significant only when the outliers were included were omitted from the figure. See Appendix A for further details. 
TABLE II. Means and Standard Deviations of the Adjusted* Plasma Lipid Variables by Apo E Genotype

\begin{tabular}{|c|c|c|c|c|c|c|c|c|c|c|c|c|}
\hline \multirow{3}{*}{$\begin{array}{l}\text { Adjusted } \\
\text { traits } \\
\text { (mg/dl) }\end{array}$} & \multicolumn{12}{|c|}{ Males } \\
\hline & \multicolumn{2}{|c|}{$\in 2 / 2(\mathbf{n}=1)$} & \multicolumn{2}{|c|}{$\epsilon 3 / 2(n=22)$} & \multicolumn{2}{|c|}{$\epsilon 3 / 3(n=73)$} & \multicolumn{2}{|c|}{$\epsilon 4 / 3(n=18)$} & \multicolumn{2}{|c|}{$€ 4 / 2(\mathrm{n}=3)$} & \multicolumn{2}{|c|}{$\epsilon 4 / 4(\mathrm{n}=1)$} \\
\hline & Mean & S.D. & Mean & S.D. & Mean & S.D. & Mean & S.D. & Mean & S.D. & Mean & S.D. \\
\hline TG & 293.63 & - & 108.30 & 47.96 & 128.42 & 49.42 & 131.79 & 66.09 & 121.13 & 28.84 & 46.57 & - \\
\hline TC & 220.04 & - & 168.38 & 24.17 & 195.63 & 33.64 & 195.85 & 36.45 & 176.63 & 63.16 & 174.15 & - \\
\hline VLDL-C & 74.38 & - & 24.35 & 11.46 & 25.95 & 11.15 & 30.17 & 17.90 & 30.02 & 13.54 & 8.24 & - \\
\hline LDL-C & 112.13 & - & 103.34 & 22.29 & 129.23 & 26.91 & 127.53 & 31.39 & 107.81 & 41.75 & 138.49 & - \\
\hline HDL-C & 33.53 & - & 40.69 & 7.94 & 40.45 & 9.75 & 38.16 & 13.66 & 38.80 & 13.16 & 27.42 & - \\
\hline HDL 2-C & 9.42 & - & 19.58 & 7.59 & 18.92 & 7.59 & 17.22 & 10.08 & 19.17 & 13.55 & 9.86 & - \\
\hline HDL3-C & 24.12 & - & 21.11 & 3.78 & 21.52 & 3.50 & 20.94 & 4.24 & 19.64 & 1.59 & 17.56 & - \\
\hline Apo B & 153.67 & - & 108.58 & 25.29 & 132.81 & 29.20 & 136.32 & 31.57 & 119.27 & 30.96 & 126.53 & - \\
\hline VLDL-B & 65.76 & - & 14.61 & 10.22 & 16.66 & 11.58 & 21.37 & 20.32 & 22.19 & 15.50 & -8.87 & - \\
\hline \multirow[t]{2}{*}{ LDL-B } & 87.75 & - & 94.06 & 19.95 & 116.23 & 23.19 & 114.95 & 23.99 & 96.96 & 21.16 & 135.26 & - \\
\hline & \multicolumn{12}{|c|}{ Females } \\
\hline \multirow{2}{*}{$\begin{array}{l}\text { Adjusted } \\
\text { traits } \\
\text { (mg/dl) }\end{array}$} & \multicolumn{2}{|c|}{$\epsilon 2 / 2(\mathrm{n}=0)$} & \multicolumn{2}{|c|}{$\epsilon 3 / 2(\mathrm{n}=15)$} & \multicolumn{2}{|c|}{$\epsilon 3 / 3(n=85)$} & \multicolumn{2}{|c|}{$\in 4 / 3(n=18)$} & \multicolumn{2}{|c|}{$\epsilon 4 / 2(n=0)$} & \multicolumn{2}{|c|}{$\epsilon 4 / 4(n=0)$} \\
\hline & Mean & S.D. & Mean & S.D. & Mean & S.D. & Mean & S.D. & Mean & S.D. & Mean & S.D. \\
\hline TG & & & 158.52 & 65.41 & 140.18 & 45.77 & 144.76 & 71.04 & & & & \\
\hline $\mathrm{TC}$ & & & 222.64 & 28.97 & 224.10 & 37.62 & 228.72 & 40.84 & & & & \\
\hline VLDL-C & & & 38.42 & 22.07 & 29.66 & 10.73 & 30.74 & 17.12 & & & & \\
\hline LDL-C & & & 137.08 & 24.80 & 149.26 & 30.76 & 149.52 & 39.32 & & & & \\
\hline HDL-C & & & 47.14 & 9.57 & 45.17 & 8.45 & 48.45 & 9.97 & & & & \\
\hline HDL2-C & & & 21.76 & 6.49 & 20.40 & 6.09 & 23.94 & 8.90 & & & & \\
\hline HDL3-C & & & 25.38 & 4.31 & 24.78 & 4.30 & 24.52 & 3.78 & & & & \\
\hline Apo B & & & 149.54 & 27.42 & 158.51 & 34.66 & 163.57 & 33.84 & & & & \\
\hline VLDL-B & & & 28.79 & 13.73 & 22.19 & 10.73 & 22.82 & 14.00 & & & & \\
\hline LDL-B & & & 120.59 & 30.82 & 136.35 & 30.72 & 140.80 & 29.83 & & & & \\
\hline
\end{tabular}

* Adjusted using the most complete model, that is, age, height, weight, BMI, glucose and uric acid all to the fourth order.

$11.0 \%$ for adjusted LDL-B. The levels for these traits were lower in males with the $\epsilon 3 / 2$ genotype than males with either the $\epsilon 3 / 3$ or $\epsilon 4 / 3$ genotypes (Table II). The lack of a statistically significant contribution of the apo $\mathrm{E}$ genotypes to interindividual variability in triglycerides, VLDL-C and VLDL-B in the subgroup was due to the removal of 2 individuals, an $\epsilon 2 / 2$ male with very high and an $\epsilon 4 / 4$ male with very low adjusted triglycerides, VLDL-C and VLDL-B levels (results not shown). For all traits, in both females and males, more than $50 \%$ of the interindividual variability was not explained by the predictors considered here.

TABLE III. Percentage of Total Sample Variability (SST) Associated With Designated Source

\begin{tabular}{|c|c|c|c|c|c|c|c|c|c|c|c|c|}
\hline \multirow{2}{*}{$\begin{array}{l}\text { Trait } \\
\text { (mg/dl) }\end{array}$} & \multicolumn{4}{|c|}{$\begin{array}{l}\text { Females } \\
(\mathrm{n}=118) \\
\end{array}$} & \multicolumn{4}{|c|}{$\begin{array}{c}\text { Males } \\
(\mathrm{n}=118)\end{array}$} & \multicolumn{4}{|c|}{$\begin{array}{c}\text { Males } \\
(\mathrm{n}=113, \epsilon 32, \epsilon 33, \epsilon 43 \text { only })\end{array}$} \\
\hline & $\mathrm{Con}^{\mathrm{a}}$ & $\mathrm{ApoE}^{\mathrm{a}, \mathrm{f}}$ & Unexp $^{a}$ & $\mathrm{SST}^{\mathrm{a}}$ & Con & $A p o E^{f}$ & Unexp & SST & Con & $A p o E^{i}$ & Unexp & SST \\
\hline TG & $44.3^{b}$ & $1.0^{\mathrm{d}}$ & 54.1 & 585,692 & $29.0^{b}$ & $12.1^{\mathrm{c}}$ & 58.9 & 482,601 & $30.6^{\mathrm{b}}$ & 2.5 & 66.9 & 420,282 \\
\hline $\mathrm{TC}$ & 22.7 & 0.2 & 77.1 & 206,294 & 19.7 & $10.5^{c}$ & 69.8 & 173,331 & 20.0 & $9.7^{\mathrm{c}}$ & 70.3 & 159,979 \\
\hline VLDL-C & 26.0 & $4.1^{\mathrm{d}, \mathrm{e}}$ & 69.9 & 30,357 & $27.1^{b}$ & $15.6^{c}$ & 57.3 & 28,208 & 28.9 & $1.7^{\mathrm{d}, \mathrm{e}}$ & 69.4 & 22,649 \\
\hline LDL-C & 23.6 & 1.6 & 74.8 & 152,196 & 25.5 & $11.7^{c}$ & 62.8 & 128,143 & 23.8 & $11.2^{\mathrm{c}}$ & 65.0 & 118,053 \\
\hline HDL-C & $35.4^{\mathrm{b}}$ & 1.6 & 63.0 & 14,170 & $32.8^{b}$ & 5.7 & 61.5 & 17,815 & $38.7^{\mathrm{b}}$ & $0.4^{\mathrm{d}, \mathrm{e}}$ & 60.9 & 17,354 \\
\hline HDL-C2 & $35.3^{b}$ & 2.9 & 61.8 & 8,108 & $35.9^{b}$ & 7.1 & 57.0 & 11,975 & $42.9^{b}$ & 0.4 & 56.7 & 11,326 \\
\hline HDL-C3 & 28.9 & 0.3 & 70.8 & 2,896 & 17.4 & 2.6 & 80.0 & 1,853 & 17.1 & 0.5 & 82.4 & 1,794 \\
\hline Apo B & 26.1 & 1.1 & 72.8 & 179,287 & 26.6 & $10.5^{\mathrm{c}}$ & 62.9 & 144,130 & 25.7 & $9.5^{\mathrm{c}}$ & 64.8 & 136,972 \\
\hline VLDL-B & $31.2^{\mathrm{b}}$ & 3.0 & 65.8 & 23,555 & 22.2 & $15.5^{\mathrm{c}}$ & 62.3 & 29,490 & 21.4 & $2.4^{\mathrm{d}, \mathrm{e}}$ & 76.2 & 23,430 \\
\hline LDL-B & 21.9 & 3.3 & 74.8 & 142,861 & $27.7^{\mathrm{b}}$ & $12.7^{\mathrm{c}}$ & 59.6 & 94,130 & 25.7 & $11.0^{\mathrm{c}}$ & 63.3 & 87,108 \\
\hline
\end{tabular}

${ }^{a}$ Con: percent sum of squares attributable to most complete model; ApoE: percent sum of squares attributable to apo E genotypes after adjustment for concomitants; Unexp: percent sum of squares not explained by concomitants and apo E genotypes; SST: total sum of squares.

${ }^{b}$ Statistically significant contribution of concomitants, $P$-value $\leq 0.05$, using an F-test with 24 and 91 (females), 88 (all males) or 86 ( $\epsilon 32$, $\epsilon 33$, E43 males only) degrees of freedom.

'Statistically significant contribution of apo $\mathbf{E}$ genotypes, $P$-value $\leq 0.05$, using an F-test with 2 and 91 (females), 5 and 88 (all males) or 2 and $86(\epsilon 32, \epsilon 33, \epsilon 43$ males only) degrees of freedom.

The intragenotypic variances among the three most common apo $\mathbf{E}$ genotypes were heterogeneous ( $P$-value $\leq 0.05$ ).

${ }^{\mathrm{e}}$ Intragenotypic variances not significantly heterogeneous when dependent variable $\log _{\mathrm{e}}$-transformed before adjustment.

Inferences about the effects of the three most common apo $\mathrm{E}$ genotypes on trait means did not change when the dependent variable was log ${ }^{-}$ transformed before the adjustment. 
In males, the intragenotypic variances of adjusted VLDL-C, VLDL-B and HDL-C were heterogeneous among the three most common apo $\mathrm{E}$ genotypes, but when the plasma lipid traits were $\log _{\mathrm{e}}$-transformed before the adjustment for concomitants, the variances were not significantly heterogeneous (these results are noted in Table III and the intragenotypic standard deviations are given in Table II). In females, the intragenotypic variances for adjusted VLDL-C and triglycerides were heterogeneous among the apo $\mathrm{E}$ genotypes, and the intragenotypic variances of adjusted triglycerides remained significantly heterogeneous when the data were first $\log _{\mathrm{e}}$-transformed. $\epsilon 3 / 3$ females were the least variable, then $\epsilon 3 / 2$ females and finally $\epsilon 4 / 3$ females were the most variable in adjusted $\log _{\mathrm{e}}$-transformed triglyceride levels.

All Pearson product moment correlations and the tests of the hypothesis of homogeneity of correlation among the common apo $\mathbf{E}$ genotypes are given in Appendices B and C. Those considered to be biologically significant because they exceeded \pm 0.30 are depicted in Figures 2 and 3. The LDL-C:LDL-B, triglyceride: VLDL-C, triglyceride:VLDL-B and VLDL-C:VLDL-B correlations were statistically significant for every gender-apo $\mathrm{E}$ genotype group. These large correlations (ranging between 0.46 and 0.94 ) that were present in all groups are considered to characterize strong invariant relationships between traits. Correlations, either positive or negative, that varied among gender and/or genotype groups are considered to characterize weak context-dependent relationships between traits.

All correlations, positive or negative, depicted in Figure 2 for the $\epsilon 3 / 3$ females were statistically significant. There were a number of other correlations in this group that were also statistically significant but were not included in Figure 2 because they did not exceed \pm 0.30 . All the correlations greater than 0.50 or less than -0.50 (medium or thick lines) were statistically significant in the $\epsilon 3 / 2$ females and all correlations depicted in Figure 2 except the HDL2-C:VLDL-B and LDL-C:VLDL-C correlations were statistically significant in the $\epsilon 4 / 3$ females. The differences in the LDLC:HDL3-C and LDL-B:HDL3-C correlations between the $\epsilon 3 / 3$ and $\epsilon 3 / 2$ females were statistically significant, while the LDL-C:triglycerides, LDL-B:triglycerides and LDL-B:VLDL-C correlation differences were marginally significant $(P \leq 0.10)$. In general, the correlations involving HDL3-C were stronger (i.e., more negative) in the $\epsilon 3 / 2$ females than the $\epsilon 3 / 3$ females, while correlations involving LDL (either LDL-C or LDL-B) and triglycerides, VLDL-C or VLDL-B were stronger (i.e., more positive) in $\epsilon 3 / 3$ females than in $\epsilon 3 / 2$ females. The $\epsilon 3 / 3$ and $\epsilon 3 / 4$ females were similar for all correlations except the LDL-B:VLDL-C and HDL2-C:LDL-C correlations, and the tests of these differences were not statistically significant. Thus, the comparison of correlation matrices indicates that the correlations in the $\epsilon 3 / 3$ females were more positive than the correlations
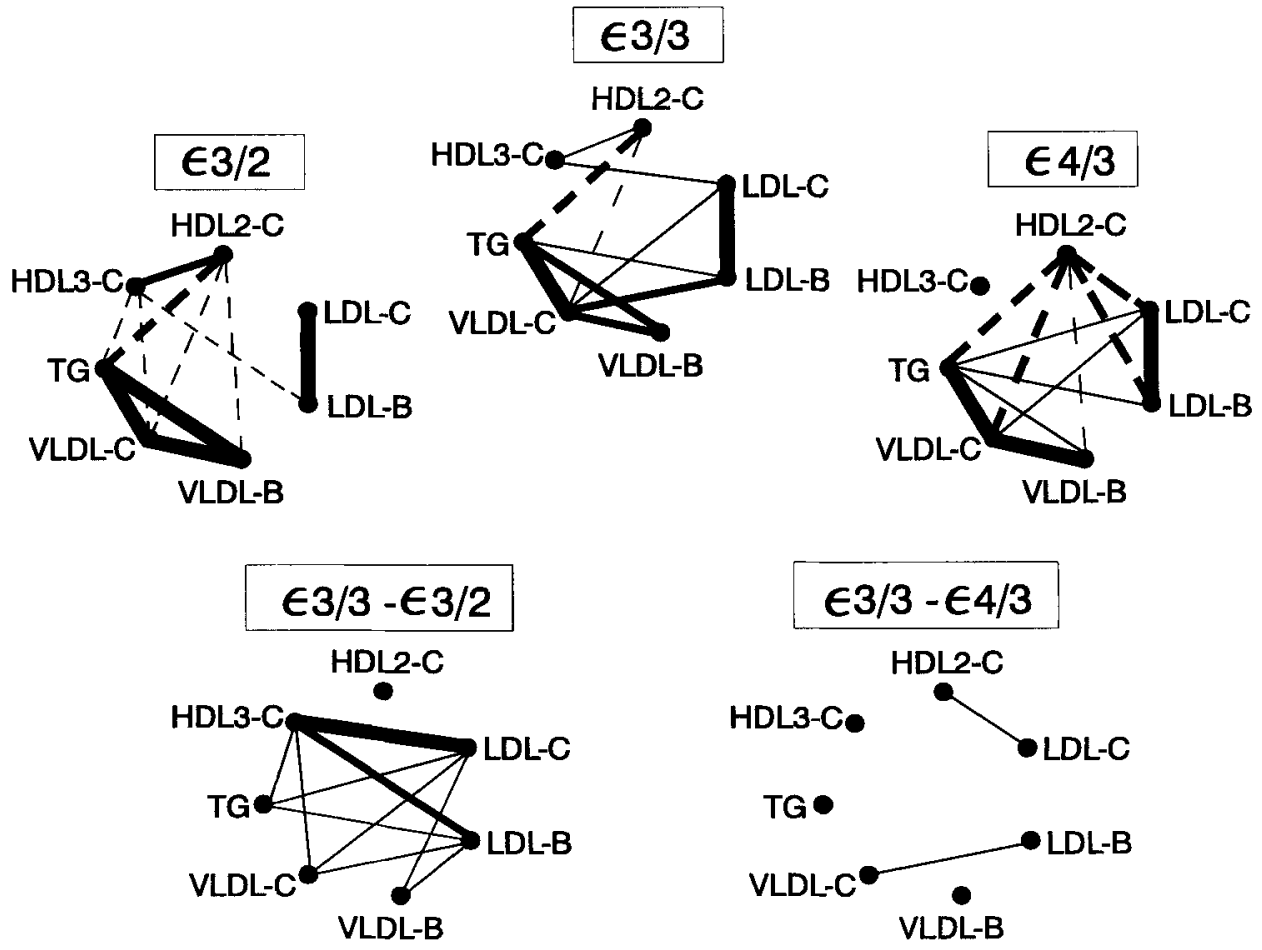

Fig. 2. Pearson product moment correlations for the three common apo Egenotypes (top) and difference maps, $\epsilon 3 / 3-\epsilon 3 / 2$ and $\epsilon 3 / 3-\epsilon 4 / 3$ (bottom) in females. Thin lines represent a correlation, or difference in correlation, between 0.3 and 0.4999 ; medium lines represent a correlation, or difference in correlation, between 0.5 and 0.6999 ; thick lines a correlation, or difference in correlation, between 0.7 and 1.0 ; thin dashed lines represent a correlation, or difference in correlation, between -0.3 and -0.4999 ; and medium dashed lines represent a correlation, or difference in correlation, between -0.5 and -0.6999 . 

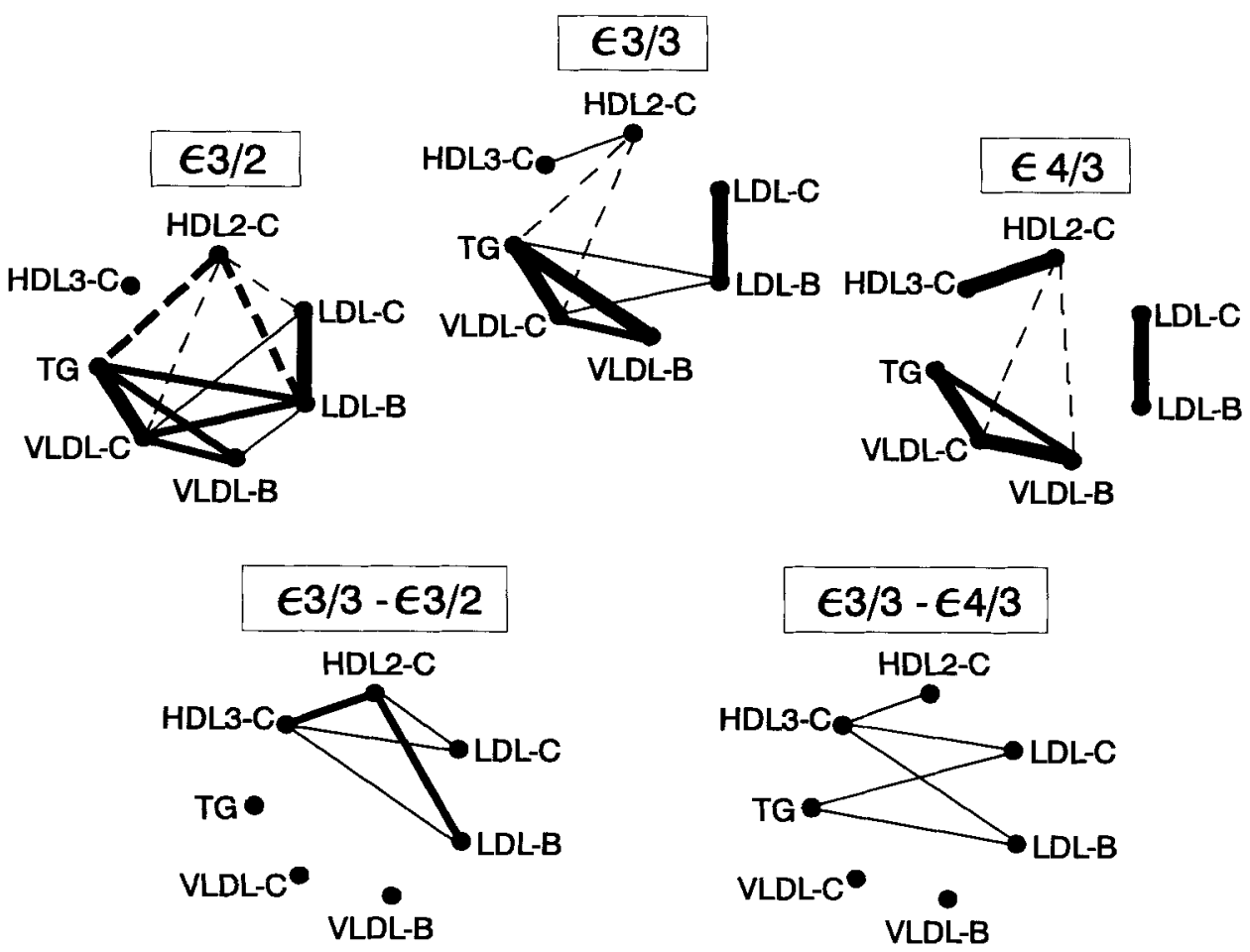

Fig. 3. Pearson product moment correlations for the three common apo E genotypes (top) and difference maps, $\epsilon 3 / 3-\epsilon 3 / 2$ and $\epsilon 3 / 3-\epsilon 4 / 3$ (bottom) in males. Thin lines represent a correlation, or difference in correlation, between 0.3 and 0.4999 ; medium lines represent a correlation, or difference in correlation, between 0.5 and 0.6999 ; thick lines a correlation, or difference in correlation, between 0.7 and 1.0 ; thin dashed lines represent a correlation, or difference in correlation, between -0.3 and -0.4999 ; and medium dashed lines represent a correlation, or difference in correlation, between -0.5 and -0.6999 .

in either the $\epsilon 3 / 2$ or $\epsilon 4 / 3$ females and that the $\epsilon 4 / 3$ females resembled the $€ 3 / 3$ females more than did the $\epsilon 3 / 2$ females.

In males, all the correlations depicted in Figure 3, except those ranging between -0.50 and +0.50 (the thin lines) in the $\epsilon 3 / 2$ and $\epsilon 4 / 3$ males, were statistically significant. As in females, the comparison of correlation matrices in males also showed that the correlations in the $\epsilon 3 / 3$ males were, in general, more positive than the correlations in either the $\epsilon 3 / 2$ or $\epsilon 4 / 3$ males. In the $\epsilon 3 / 3$ $\epsilon 3 / 2$ difference map, all of the differences greater than 0.3 involved LDL-C, LDL-B, HDL2-C and HDL3-C, and all except the differences in the HDL3-C:LDL-B and HDL3-C:LDL-C correlations were statistically significant. Generally the correlations involving HDL2-C were stronger (i.e., more negative) in $\epsilon 3 / 2$ males than $\epsilon 3 / 3$ males. In the $\epsilon 3 / 3-\epsilon 4 / 3$ difference map, none of the tests of the differences depicted in Figure 3 were statistically significant. In conclusion, as in the females, the $\epsilon 4 / 3$ males were more similar to the $\epsilon 3 / 3$ males than the $\epsilon 3 / 2$ males and the adjusted plasma lipid traits were more positively correlated in $\epsilon 3 / 3$ males than in the others.

As mentioned earlier, the interindividual variances of many of the plasma lipid traits were heterogeneous between the genders. Thus, tests of the homogeneity of correlation between the genders would be uninformative with respect to covariation differences [Reilly et al., 1994]. Even so, there are some general trends that can be detected. As can be seen in Figure 4, the correlations in the $\epsilon 3 / 3$ males and females were very similar. In contrast, the males and females appeared to have heterogeneous correlations when they were compared within the $\epsilon 3 / 2$ or $\epsilon 4 / 3$ genotypes. In general, the correlations were stronger in the $\epsilon 3 / 2$ males than in the $\epsilon 3 / 2$ females, while the correlations were stronger in the $\epsilon 4 / 3$ females than in the $\epsilon 4 / 3$ males. Thus, the $\epsilon 4 / 3$ and $\epsilon 3 / 2$ genotypes deviated from the more common $\epsilon 3 / 3$ genotype with regard to correlation, as discussed above, but how they deviated may be gender dependent.

\section{DISCUSSION}

Octogenarians are a particularly appropriate subset of the population for studying the effects of aging and gender on the impact of variation in the apo $E$ gene on the genetic architecture of the phenotypic distributions of plasma measures of lipid metabolism. This is because octogenarian women are well past menopause, the impact of variation in age is minimal and octogenarians represent a selected population of survivors. Based on previous studies of nonoctogenarians, it is generally accepted that the apo $\epsilon 4$ allele is associated with increased, and the apo $\epsilon 2$ allele with decreased, risk of CAD [Cumming and Robertson, 1984; Davignon et al., 1988b; Kuusi et al., 1989; Hixson et al., 1991; Pedro-Botet et al., 1992; Eichner et al., 1993; Stengård et al., 1995]. Therefore, it is expected that the relative frequency of apo $\epsilon 4$ will be decreased and apo $\epsilon 2$ increased in individuals who reach their eightieth decade as compared to subjects of a younger age group. This 


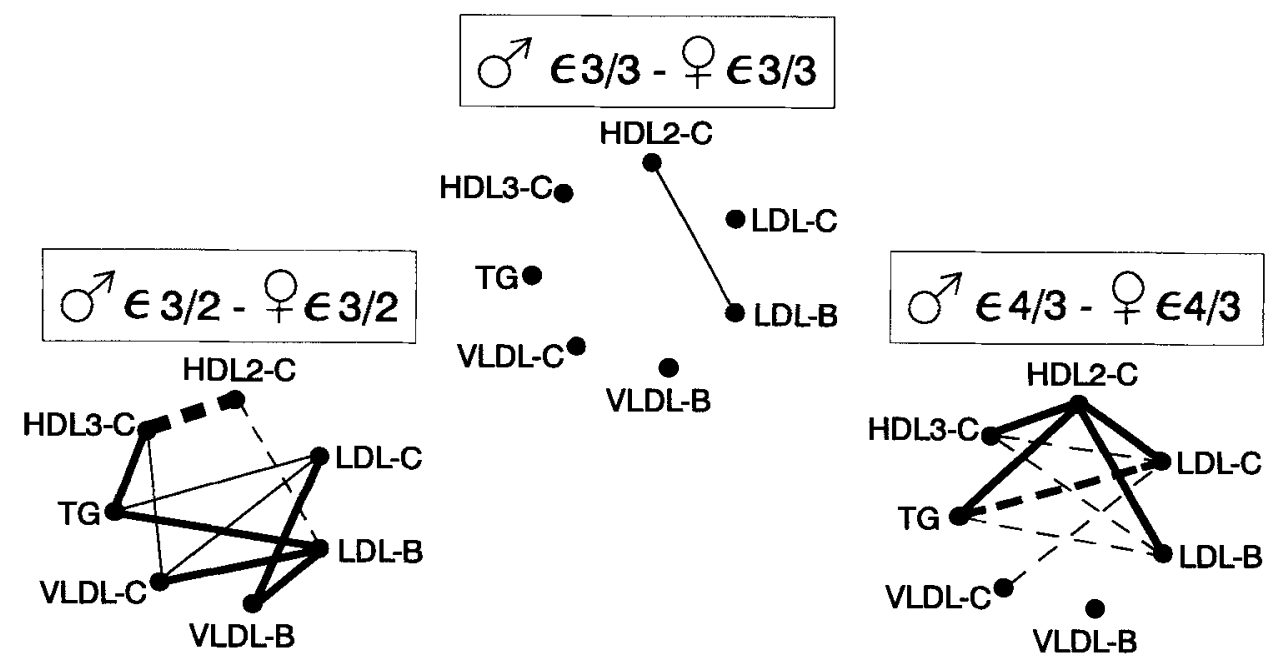

Fig. 4. Differences in correlation between males and females by apo $\mathrm{E}$ genotype. Thin lines represent a difference in correlation between 0.3 and 0.4999 ; medium lines represent a difference in correlation between 0.5 and 0.6999 ; thick lines a difference in correlation between 0.7 and 1.0 ; thin dashed lines represent a difference in correlation between -0.3 and -0.4999 ; medium dashed lines represent a difference in correlation between -0.5 and -0.6999 , and thick dashed lines represent a difference in correlation between -0.7 and -1.0 .

hypothesis is supported by the relative frequencies observed in this sample [Davignon et al., 1988a, 1989] and others [Cauley et al., 1993; Eggertsen et al., 1993; Kervinen et al., 1994; Louhija et al., 1994; Schächter et al., 1994].

In this sample of octogenarians, the males were healthier than the females with regard to plasma lipid levels and presence of disease. The plasma lipid means and variances were within the range reported in other studies of the elderly and as such this sample of octogenarians appears to be representative of octogenarians in general [Nicholson et al., 1979; Alvarez et al., 1984; Luc et al., 1991; Tietz et al., 1992]. The mean levels of the plasma lipids in this sample of octogenarian males were, in general, only slightly higher than those observed in males from a sample of younger Canadian individuals (mean age of 39 in males and 37 in females) [Xhignesse et al., 1991]. In contrast, the octogenarian females had much higher lipid levels than those observed in younger females. This result was not unexpected because previous studies have documented that average plasma lipid levels increase with age in both genders, that females have higher average levels than males in the elderly [Kritchevsky, 1978; Connor et al., 1982; Abbott et al., 1983; Kottke et al., 1991], and that average total cholesterol, LDL-C and triglyceride levels begin to decrease in the last decades of life [Castelli et al., 1977; Dedonder-Decoopman et al., 1980; Herschcopf et al., 1982; National Center for Health Statistics et al., 1986]. The cross-over of the male and female levels while aging [Williams et al., 1993] may be due to a steeper rise in plasma lipid levels in females than in males or due to the death of those males with high plasma lipid levels [Lamon-Fava et al., 1994]. The latter hypothesis is supported by the differences in relative apo $\mathbf{E}$ allele frequencies in samples of young and elderly individuals. Thus, it appears that the male and female octogenarians in this sample are at very different stages in the aging process with respect to lipid metabolism and also have differential selective mortality, even though they are chronologically the same age.

The contribution of variation in indices of aging and lifestyle, i.e., concomitants, to interindividual plasma lipid variability is gender-, age- and trait-dependent. As reported here, the relationships between plasma lipid traits and measures of aging and lifestyle, i.e., concomitants, differed among traits and between male and female octogenarians. So, as pointed out by others, the study of the causes of interindividual differences in levels of plasma lipid traits must be carried out separately in males and females [Reilly et al., 1990, 1991, 1992; Kaprio et al., 1991; Xhignesse et al., 1991; Kessling et al., 1992]. Also, the concomitants explained more of the interindividual trait variability (estimated as the percent sum of squares) in this sample of octogenarians than in a sample of healthy younger individuals, in which the same adjustment was used [Xhignesse et al., 1991], in all traits except total cholesterol in males and LDL-C in females. This result could be due to the octogenarians having increased sum of squares attributable to the concomitants, especially glucose and uric acid levels, and/or decreased total sum of squares. The standard deviations of all the plasma lipid traits were greater in the octogenarians than in the sample of younger individuals [Xhignesse et al., 1991]. Thus, it may be inferred that the greater interindividual variability in plasma lipid levels in octogenarians reflects their exposure to a larger range of environmental factors, indexed by the concomitants measured here, and/or their longer exposure to the influence of a particular environmental factor. It also makes clear that inferences drawn from studies of younger individuals about the contribution of concomitant variability to plasma lipid trait variability are not applicable to older individuals.

The impact of apo E genotype variation on measures of LDL metabolism in this sample of male octogenarians confirms what has been observed by others in 
younger samples [Sing and Davignon, 1985; Boerwinkle et al., 1987; Davignon et al., 1988b; Kaprio et al., 1991; Reilly et al., 1991; Xhignesse et al., 1991; Davignon, 1993]. But it should be noted that the association in octogenarian males was primarily due to the lower mean levels of these traits in $\epsilon 3 / 2 \mathrm{~s} ; \epsilon 4 / 3 \mathrm{~s}$ had adjusted total cholesterol, LDL-C, apo B and LDL-B levels very close to and even below those seen in $\epsilon 3 / 3 \mathrm{~s}$. Thus, it can be hypothesized that the decrease in the frequency of the apo $\epsilon 4$ allele observed in the males may be due to those males with the apo $\epsilon 4 / 3$ (and perhaps apo $\epsilon 4 / 4$ ) genotype and the highest levels of plasma LDL-C and apo B levels not being sampled, either because of the sample selection criteria or death from CAD or other chronic diseases such as Alzheimer's disease [Poirier et al., 1993; Strittmatter et al., 1993]. In contrast to the males, variation in the apo $\mathrm{E}$ gene did not have a statistically significant impact on adjusted plasma lipid levels in this sample of female octogenarians. Thus, even though it has been hypothesized by others that the impact of apo $\mathrm{E}$ genotype variation is homogeneous across populations [Hallman et al., 1991], the results reported here suggest instead that apo $\mathrm{E}$ allele frequencies and effects are context-dependent within this particular subdivision of the Canadian population. This result is supported by a study of individuals aged 5-90 which found that the variance in measures of lipid metabolism associated with the apo $\mathrm{E}$ genotypes is dependent on gender and age (Zerba, personal communication, 1995).

Results of studies in younger individuals have been inconsistent with regard to whether individuals with the $\epsilon 3 / 2$ genotype, in general, have higher or lower triglyceride levels compared with individuals with either the $\epsilon 3 / 3$ or $\epsilon 4 / 3$ genotypes (reviewed by Davignon, 1993). Davignon hypothesized that the inconsistent results may be due to a difference in the impact of the apo E polymorphism in "healthy" versus "unhealthy" individuals; that is, the $\epsilon 2$ allele may be associated with lower triglyceride levels in "healthy" individuals and with higher triglyceride levels in others [Davignon, 1993]. This hypothesis is supported by this study; the $€ 3 / 2$ genotype was associated with lower triglyceride levels in males (who in general were free from CAD risk factors) and with higher triglyceride levels in females (who appeared to be less healthy than the males) as compared to the $\epsilon 3 / 3$ or $\epsilon 4 / 3$ genotypes. These results should be taken as preliminary because the triglyceride differences between the apo $\mathrm{E}$ genotypes within each gender were not statistically significant. Even so, these results further support the hypothesis that the impact of variation in the apo $\mathrm{E}$ gene is context-dependent.

Variation in the apo E gene appeared to have little or no effect on intragenotypic trait variance in this sample of octogenarians. This result is supported by a study of teenage twins in which the null hypothesis that apo $\mathrm{E}$ does not act as a variability gene [Berg, 1990] was not rejected [de Knijff et al., 1993]. In contrast, the intragenotypic variances of many traits including total cholesterol, triglycerides, apo B, apo AII, apo $\mathrm{E}$ and apo CIII were found to be heterogeneous among apo E genotypes in a sample of adults [Kaprio et al., 1991; Reilly et al., 1991]. These contradictory results may reflect a developmental change in the action of the apo $\mathrm{E}$ gene product. Heterogeneity of variance among genotype classes is thought to be due, in part, to gene by environment interaction [Reilly et al., 1991; Zerba and Sing, 1993]. Children have experienced relatively short times of exposure to different environments, implying that the smaller impact of apo $E$ on variances could not be detected [de Knijff et al., 1993]. In contrast, an impact of apo $\mathrm{E}$ on variances would be detected in adults because of their exposure to a larger range of environmental factors and/or their longer exposure to a particular environmental factor. Finally, in octogenarians, the marginal, average effects of a single gene are likely to be small relative to the total accumulation of a lifetime of effects of interactions between a large range of environmental exposures and genetic variation [Zerba and Sing, 1993]. This is supported by the result that in both male and female octogenarians in this sample, more than $50 \%$ of the interindividual variability for all plasma lipid traits was not explained by the predictors considered here.

The apo $\mathrm{E}$ gene acts not only as a level and variability gene, but also as a covariability gene [Reilly et al., 1994]. In other words, variation in the apo $E$ gene associates with differences in the relationships between the agents involved in lipid metabolism. Because the previous studies [Boerwinkle et al., 1987; Reilly et al., 1994] that estimated the effect of apo $E$ on correlations used different plasma lipid traits, adjusted for concomitants in a different way, had different relative apo $\mathrm{E}$ allele frequencies and, in one study [Boerwinkle et al., 1987], combined males and females, it is inappropriate to make comparisons of specific correlations with the estimates reported here.

Despite the above caveats, certain general conclusions can be made. First, the strong invariant forces between adjusted plasma lipid traits identified in this sample of octogenarians, LDL-C:LDL-B, triglycerides: VLDL-C, triglycerides: VLDL-B and VLDL-C :VLDL-B, have been observed by others in samples of younger individuals [Reilly et al., 1994; Roy et al., 1995]. This suggests that the strong forces among agents involved in lipid metabolism measure characteristics common to all age, gender and genotype groups. These correlations may reflect the long evolutionary history of the lipid metabolism system [Weiss, 1993].

In contrast, those correlations that were heterogeneous among genotype groups reflect the effects of short term evolutionary events, such as the creation of the apo E polymorphism. Correlations between plasma lipid traits have been found to be heterogeneous among the common apo $\mathrm{E}$ genotypes in all other studies that addressed this question [Boerwinkle et al., 1987; Després et al., 1993; Reilly et al., 1994], supporting the generality of the inferences reported here.

Finally, the differences in correlations between the genders and between samples of younger and older individuals may reflect the epigenetic effects of the gender-specific physiological changes of aging. In the one other study in which males and females were considered separately, gender influenced the manner in which 
the correlations differed among the apo $\mathrm{E}$ genotypes, suggesting this result is not peculiar to our study of octogenarians [Reilly et al., 1994]. Although we cannot compare specific correlations among the different studies because of the reasons mentioned above, it is clear that the strength of some relationships among plasma lipid levels are age-dependent. This is supported by Reilly et al. [1990] who demonstrated heterogeneity of the variance-covariance matrices of pairs of plasma lipid and lipoprotein traits among three generations (children, parents and grandparents). In summary, the observed correlations reflect the effects of changes in culture and the genome over three time scales: long evolutionary history, short evolutionary history and lifecycle history.

\section{CONCLUSIONS}

The results from this study of octogenarians suggest that aging can be thought of in two ways: as an index for selection and for physiological change. We hypothesize that octogenarian males represent a sample of individuals in which selective mortality has occurred. This follows from the observation that most of the plasma lipid traits were less variable in the octogenarian males than in the females. Also, the average lipid levels in these males resemble those measured in samples of younger adult males and the impact of variation in the apo $\mathbf{E}$ gene on mean plasma lipid levels is, in general, the same. But octogenarian males with the $\epsilon 4 / 3$ genotype did not have higher LDL-C or apo B levels than $\epsilon 3 / 3$ or $\epsilon 3 / 2$ males. The relative frequency of the $\epsilon 4$ allele was also found to be reduced in this sample, suggesting that those $\epsilon 4 / 3$ individuals with high lipid levels were not sampled, either because of the sample selection criteria or because they were selectively removed from the population by early death from CAD or other chronic diseases such as Alzheimer's disease. In support of this selective mortality hypothesis, a longitudinal study of Finnish men demonstrated that the $\epsilon 4$ allele was associated with increased CAD mortality [Stengård et al., 1995]. Variation in only a few genes has previously been associated with survival in humans [Proust et al., 1982; Takata et al., 1987; Kramer et al., 1991; Lagaay et al., 1991]; apo E joins the list as an example of a gene involved in influencing variation in the aging process [Kervinen et al., 1994; Schächter et al., 1994].

Female octogenarians in this sample had a much more severe $\mathrm{CAD}$ risk profile than males and thus male and female octogenarians may be at different physiological ages. We hypothesize that female octogenarians, as a group, are just entering a period of increased mortality from CAD and other chronic diseases. This would explain the higher incidence of CAD, hypertension and hypothyroidism in the females and their severe CAD risk profile. Thus, the results from this study suggest that age is an index for the rate of selective mortality due to CAD and other chronic diseases but that the rates are different in female and male octogenarians.
Aging is also an index of physiological change, and the male and female octogenarians are at different physiological stages not only with respect to lipid metabolism in general, but also with respect to the impact of variation in the apo $\mathrm{E}$ gene on lipid metabolism. The plasma lipid trait means and variances were higher in this sample of female octogenarians than what has been observed in samples of younger individuals. Also, the concomitants explained more of the interindividual plasma lipid trait variability in this sample of octogenarians than what has been found in other samples. Thus, the means and variances of plasma lipid levels as well as the contribution of environmental factors to interindividual variability in plasma lipid levels change as a function of aging.

Our study contributes to the growing body of evidence that, in addition to having an impact on average trait levels, common allelic variations in the apo $\mathrm{E}$ gene associate with differences in the pattern of relationships between intermediate biological traits in the network of agents that link genome type variation with variation in risk of disease. Further, this study documents that the genetic architecture of a quantitative CAD risk factor trait cannot be a static characterization. Instead it must be a dynamic summarization that is dependent on the context defined by exposures to environments during the lifecycle that are indexed by gender, age, and the population of inference.

\section{ACKNOWLEDGMENTS}

The authors acknowledge the important contribution made by Dr. Daniel Bouthillier during the initial phases of this study. We also thank Mrs. Suzanne Quidoz, RN and Angele Richard, RN for obtaining blood samples, Ann Chamberland, Louis-Jacques Fortin, Lucie Boulet and Michel Tremblay for their technical assistance and Drs. Sharon Reilly and Jari Stengård for their helpful discussion. This work was supported by grants from the Medical Research Council of Canada (MA-5427), the Medical Research Council/CIBA-Geigy Canada Ltd. University/Industry program (UI-11407), and by La Succession J.A. de Seve.

\section{REFERENCES}

Abbott RD, Garrison RJ, Wilson PWF, Epstein FH, Castelli WP, Feinleib M, LaRue C (1983): Joint distribution of lipoprotein cholesterol classes: The Framingham Study. Arteriosclerosis 3:260-272.

Allain CC, Poon LS, Chan CSG, Richmond W, Fu PC (1974): Enzymatic determination of total serum cholesterol. Clin Chem 20:470-475.

Alvarez C, Orejas A, Gonzalez S, Diaz R, Colomo LF (1984): Reference intervals for serum lipids, lipoproteins, and apoproteins in the elderly. Clin Chem 30:404-406.

Berg K (1990): Level genes and variability genes in the etiology of hyperlipidemia and atherosclerosis. In Berg $K$, Retterstol $N$, Refsum S (eds): "From Phenotype to Gene in Common Disorders." Copenhagen: Munksgaard, A/S Int., pp. 77-91.

Boerwinkle E, Visvikis S, Welsh D, Steinmetz J, Hanash SM, Sing CF (1987): The use of measured genotype information in the analysis of quantitative phenotypes in man. II. The role of the apolipoprotein $\mathbf{E}$ polymorphism in determining levels, variability, and covariability of cholesterol, betalipoprotein, and triglycerides in a sample of unrelated individuals. Am J Med Genet 27:567-582.

Bouthillier D, Sing CF, Davignon J (1983): Apolipoprotein E phenotyping with a single gel method: Application to the study of informative matings. J Lipid Res 24:1060-1069. 
Castelli WP, Cooper GR, Doyle JT, Garcia-Palmieri M, Gordon T Hames C, Hulley SB, Kagan A, Kuchmak M, McGee D, Vicic WJ (1977): Distribution of triglyceride and total, LDL and HDL cholesterol in several populations: A cooperative lipoprotein phenotyping study. J Chron Dis 30:147-169.

Cauley JA, Eichner JE, Kamboh MI, Ferrell RE, Kuller LH (1993): Apo $\mathrm{E}$ allele frequencies in younger (age 42-50) vs. older (age 65-90) women. Genet Epidemiol 10:27-34.

Connor SL, Connor WE, Sexton G, Calvin L, Bacon S (1982): The effects of age, body weight and family relationships on plasma lipoproteins and lipids in men, women and children of randomly selected families. Circulation 65:1290-1298.

Cumming AM, Robertson FW (1984): Polymorphism at the apoprotein-E locus in relation to risk of coronary disease. Clin Genet $25: 310-313$

Davignon J (1991): Apolipoprotein E polymorphism, dyslipidemia and atherosclerosis. Nutr Metab Cardiovasc Dis 1:53-56.

Davignon J (1993): Apolipoprotein E polymorphism and atherosclerosis. In Born GVR, Schwartz CJ (eds): "New Horizons in Coronary Heart Disease." London: Current Sciences, pp. 5.1-5.21.

Davignon J, Bouthillier D, Nestruck AC, Sing CF (1988a): Apolipoprotein $\mathrm{E}$ polymorphism and atherosclerosis: Insights from a study in octogenarians. Trans Amer Clin Climatol Assoc 99:100-110.

Davignon J, Gregg RE, Sing CF (1988b): Apolipoprotein E polymorphism and atherosclerosis. Arteriosclerosis 8:1-21.

Davignon J, Roederer G, Trudeau P, Dallongeville J, Sing CF (1989): Atherogenic dyslipidemias: Disorders of apolipoprotein $\mathbf{E}$ isoforms. In Crepaldi G, Gotto AM, Manzato E, Baggio G (eds): "Atherosclerosis VIII." Netherlands: Elsevier Science Publishers, pp. 389-393

de Knijff P, Boomsma DI, de Wit E, Kempen HJM, Leuven JAG, Frants RR, Havekes LM (1993): The effect of the apolipoprotein E phenotype on plasma lipids is not influenced by environmental variability: Results of a Dutch twin study. Hum Genet 91:268-272.

Dedonder-Decoopman E, Fievet-Desreumaux C, Campos E, Moulin S, Dewailly P, Sezille G, Jaillard J (1980): Plasma levels of VLDL- + LDL-cholesterol, HDL-cholesterol, triglycerides and apoproteins B and A-I in a healthy population. Influence of several risk factors. Atherosclerosis 37:559-568.

Després J-P, Verdon M-F, Moorjani S, Pouliot M-C, Nadeau A, Bouchard C, Tremblay A, Lupien PJ (1993): Apolipoprotein E polymorphism modifies relation of hyperinsulinemia to hypertriglyceridemia. Diabetes 42:1474-1481.

Eggertsen G, Tegelman R, Ericsson S, Angelin B, Berglund L (1993): Apolipoprotein $\mathbf{E}$ polymorphism in a healthy Swedish population: Variation of allele frequency with age and relation to serum lipid concentrations. Clin Chem 39:2125-2129.

Eichner JE, Kuller LH, Orchard TJ, Grandits GA, McCallum LM, Ferrell RE, Neaton JD (1993): Relation of apolipoprotein $E$ phenotype to myocardial infarction and mortality from coronary artery disease. Am J Cardiol 71:160-165.

Gidez LI, Miller GJ, Burstein M, Slagle S, Eder HA (1982): Separation and quantitation of subclasses of human high density lipoproteins by a simple precipitation procedure. J Lipid Res 23:1206-1223.

Hallman DM, Boerwinkle E, Saha N, Sandholzer C, Menzel HJ, Csazar A, Utermann G (1991): The apolipoprotein E polymorphism: A comparison of allele frequencies and effects in nine populations. Am J Hum Genet 49:338-349.

Hennekens CH, Buring JE (1987): "Epidemiology in Medicine." Boston: Little, Brown and Company, pp. 30-34

Herschcopf RJ, Elahi D, Andres R, Baldwin HL, Raizes GS, Schocken DD, Tobin JD (1982): Longitudinal changes in serum cholesterol in man: an epidemiologic search for an etiology. J Chron Dis 35: 101-114.

Hixson JE, Pathobiological Determinants of Atherosclerosis in Youth (PDAY) Research Group (1991): Apolipoprotein E polymorphisms affect atherosclerosis in young males. Arterioscler Thromb 11: $1237-1244$

Kageyama N (1971): A direct colorimetric determination of uric acid in serum and urine with uricase-catalase system. Clin Chim Acta $31: 421-426$.

Kaprio J, Ferrell RE, Kottke BA, Kamboh MI, Sing CF (1991): Effects of polymorphisms in apolipoproteins $\mathrm{E}, \mathrm{A}-\mathrm{IV}$, and $\mathrm{H}$ on quantitative traits related to risk for cardiovascular disease. Arterioscler Thromb 11:1330-1348.
Kervinen K, Savolainen MJ, Salokannel J, Hynninen A, Heikkinen J, Ehnholm C, Koistinen MJ, Kesäniemi YA (1994): Apolipoprotein E and $\mathbf{B}$ polymorphisms - longevity factors assessed in nonagenarians. Atherosclerosis 105:89-95.

Kessling A, Ouellette S, Bouffard O, Chamberland A, Bétard C, Selinger E, Xhignesse M, Lussier-Cacan S, Davignon J (1992): Patterns of association between genetic variability in apolipoprotein (apo) B, apo AI-CIII-AIV, and cholesterol ester transfer protein gene regions and quantitative variation in lipid and lipoprotein traits: Influence of gender and exogenous hormones. Am J Hum Genet 50:92-106.

Kottke BA, Moll PP, Michels VV, Weidman WH (1991): Levels of lipids, lipoproteins, and apolipoproteins in a defined population. Mayo Clin Proc 66:1198-1208.

Kramer J, Fulop T, Rajezy K, Tuan NA, Fust G (1991): A marked drop in the incidence of the null allele of the $B$ gene of the fourth component of complement $\left(\mathrm{C}_{4} \mathrm{~B}^{*} \mathrm{Q} 0\right)$ in elderly subjects: $\mathrm{C} 4 \mathrm{~B} * \mathrm{Q} 0$ as a probable negative selection factor for survival. Hum Genet $86: 595-598$

Kritchevsky D (1978): How aging affects cholesterol metabolism. Postgrad Med 63:133-138.

Kuusi T, Nieminen MS, Ehnholm C, Yki-Järvinen H, Valle M, Nikkilä EA, Taskinen M-R (1989): Apoprotein E polymorphism and coronary artery disease. Increased prevalence of apolipoprotein E-4 in angiographically verified coronary patients. Arteriosclerosis 9:237-241.

Lagaay AM, D'Amaro J, Ligthart GJ, Schreuder GM, van Rood JJ, Hijmans W (1991): Longevity and heredity in humans. Association with the human leucocyte antigen phenotype. Ann NY Acad Sci 621:78-89.

Lamon-Fava S, Jenner JL, Jacques PF, Schaefer EJ (1994): Effects of dietary intakes on plasma lipids, lipoproteins, and apolipoproteins in free-living elderly men and women. Am J Clin Nutr 59:32-41.

Lipid Research Clinies Program (1974): Manual of laboratory operations, vol. 1: Lipid and lipoprotein analysis. (DHEW publication no (NIH) 75-628). Washington, DC: US Government Printing Office, pp 1-81.

Louhija J, Miettinen HE, Kontula K, Tikkanen MJ, Miettinen TA Tilvis RS (1994): Aging and genetic variation of plasma apolipoproteins. Relative loss of the apolipoprotein E4 phenotype in centenarians. Arterioscler Thromb 14:1084-1089

Luc G, Bard JM, Lussier-Cacan S, Bouthillier D, Parra HJ, Fruchart JC, Davignon J (1991): High-density lipoprotein particles in octogenarians. Metabolism 40:1238-1243.

National Center for Health Statistics, Fulwood $R$, Kalsbeek W Rifkind B, Russell-Briefel R, Muesing R, LaRosa J, Lippel K (1986): Total serum cholesterol levels of adults 20-74 years of age: United States, 1976-1980. (Vital and health statistics. Series II No. 236. DHHS Pub. No. (PHS) 86-1686. Public Health Service). Washington, DC: US Government Printing Office.

Neter J, Wasserman W, Kutner MH (1985): "Applied Linear Statistical Models." Homewood, Illinois: Irwin, pp. 226-327.

Nicholson J, Gartside PS, Siegel M, Spencer W, Steiner PM, Glueck CJ (1979): Lipid and lipoprotein distributions in octo- and nonagenarians. Metabolism 28:51-55.

Pedro-Botet J, Sentí M, Nogués $\mathrm{X}$, Rubiés-Prat J, Roquer J, D'Olhaberriague L, Olivé J (1992): Lipoprotein and apolipoprotein profile in men with ischemic stroke. Role of lipoprotein(a), triglyceride-rich lipoproteins, and apolipoprotein $\mathbf{E}$ polymorphism. Stroke 23:1556-1562.

Poirier J, Davignon J, Bouthillier D, Kogan S, Bertrand P, Gauthier S (1993): Apolipoprotein $\mathbf{E}$ polymorphism and Alzheimer's disease. Lancet 342:697-699.

Proust J, Moulias R, Fumeron F, Bekkhoucha F, Busson M, Schmid M, Hors J (1982): HLA and longevity. Tissue Antigens 19:168-173.

Reardon MF, Poapst ME, Uffelman KD, Steiner G (1981): Improved method for quantitation of $\mathbf{B}$ apoprotein in plasma lipoproteins by electroimmunoassay. Clin Chem 27:892-895.

Reilly SL, Ferrell RE, Kottke BA, Kamboh MI, Sing CF (1991): The gender-specific apolipoprotein $\mathrm{E}$ genotype influence on the distribution of lipids and apolipoproteins in the population of Rochester, MN. I. Pleiotropic effects on means and variances. Am J Hum Genet 49:1155-1166. 
Reilly SL, Ferrell RE, Kottke BA, Sing CF (1992): The gender specific apolipoprotein $\mathrm{E}$ genotype influence on the distribution of plasma lipids and apolipoproteins in the population of Rochester, Minnesota. II. Regression relationships with concomitants. Am J Hum Genet 51:1311-1324.

Reilly SL, Ferrell RE, Sing CF (1994): The gender-specific apolipoprotein $\mathrm{E}$ genotype influence on the distribution of plasma lipids and apolipoproteins in the population of Rochester, MN. III. Correlations and covariances. Am J Hum Genet 55:1001-1018.

Reilly SL, Kottke BA, Sing CF (1990): The effects of generation and gender on the joint distributions of lipid and apolipoprotein phenotypes in the population at large. J Clin Epidemiol 43:921-940.

Richterich R, Dauwalder H (1971): Zur Bestimmung der Plasmaglukosekonzentration mit der Hexokinase-glucose-6-phosphatdehydrogenase-Methode. Schweiz Med Wochenschr 101:615-618.

Rosseneu M, Vinaimont $N$, Vercaemst R, Dekeersgieter W, Belpaire $F$ (1981): Standardization of immunoassays for the quantitation of plasma apo B protein. Anal Biochem 116:204-210.

Roy M, Sing CF, Bétard C, Davignon J (1995): Impact of a common mutation of the LDL receptor gene, in French-Canadian patients with familial hypercholesterolemia, on means, variances and correlations among traits of lipid metabolism. Clin Genet 47:59-67.

Sampson EJ, Demers LM, Krieg AF (1975): Faster enzymatic procedure for serum triglycerides. Clin Chem 21:1983-1985.

SAS Institute Inc. (1989): "SAS/STAT@ User's Guide, Version 6." Cary, NC: SAS Institute Inc.

Schächter F, Faure-Delanef L, Guénot F, Rouger H, Froguel P, Lesueur-Ginot L, Cohen D (1994): Genetic associations with human longevity at the APOE and ACE loci. Nature Genet 6:29-32.

Sing CF, Davignon J (1985): Role of the apolipoprotein E polymorphism in determining normal plasma lipid and lipoprotein variation. Am J Hum Genet 37:268-285.
Sokal RR, Rohlf FJ (1981): "Biometry." New York: W.H. Freeman and Company, pp 402-408, 583-591.

Stengård JH, Zerba KE, Pekkanen J, Ehnholm C, Nissinen A, Sing CF (1995): Apo E polymorphism predicts death from coronary heart disease in a longitudinal study of elderly Finnish men. Circulation 91:265-269.

Strittmatter WJ, Saunders AM, Schmechel D, Pericak-Vance M, Enghild J, Salvesen GS, Roses AD (1993): Apolipoprotein E: highavidity binding to $\beta$-amyloid and increased frequency of type 4 allele in late-onset familial Alzheimer disease. Proc Natl Acad Sci USA 90:1977-1981.

Takata H, Suzuki M, Ishii T, Sekiguchi S, Iri H (1987): Influence of major histocompatibility complex region genes on human longevity among Okinawan-Japanese centenarians and nonagenarians. Lancet:824-826.

Tietz NW, Shuey DF, Wekstein DR (1992): Laboratory values in fit aging individuals-sexagenarians through centenarians. Clin Chem 38:1167-1185.

Weiss KM (1993): "Genetic Variation and Human Disease. Principles and Evolutionary Approaches." Cambridge: Cambridge University Press, pp 30-36.

Williams EL, Winkleby MA, Fortmann SP (1993): Changes in coronary heart disease risk factors in the 1980s: Evidence of a malefemale crossover effect with age. Am J Epidemiol 137:1056-1067.

Xhignesse M, Lussier-Cacan S, Sing CF, Kessling AM, Davignon J (1991): Influences of common variants of apolipoprotein $\mathrm{E}$ on measures of lipid metabolism in a sample selected for health. Arterioscler Throm 11:1100-1110.

Zerba KE, Sing CF (1993): The role of genome type-environment interaction and time in understanding the impact of genetic polymorphisms on lipid metabolism. Curr Opin Lipid 4:152-162. 
APPENDIX A. Percentage of Sample Variability Associated With Designated Concomitants

\begin{tabular}{|c|c|c|c|c|c|c|c|c|}
\hline \multirow{3}{*}{$\begin{array}{l}\text { Regression model } \\
\text { concomitants }^{\mathrm{b}}\end{array}$} & \multicolumn{4}{|c|}{ TG } & \multicolumn{4}{|c|}{ TC } \\
\hline & \multicolumn{2}{|c|}{ Females } & \multicolumn{2}{|c|}{ Males } & \multicolumn{2}{|c|}{ Females } & \multicolumn{2}{|c|}{ Males } \\
\hline & Partial $^{\mathrm{a}}$ & Total $^{2}$ & Partial & Total & Partial & Total & Partial & Total \\
\hline Age & 1.6 & 1.6 & 0.0 & 0.0 & 1.6 & 1.6 & 0.0 & 0.0 \\
\hline Height & 1.2 & 2.8 & 0.6 & 0.6 & 0.2 & 1.8 & 0.6 & 0.6 \\
\hline Height $^{2}$ & 0.7 & 3.5 & $2.1^{\mathrm{e}}$ & 2.7 & $3.9^{\mathrm{c}, \mathrm{d}}$ & 5.7 & 0.0 & 0.6 \\
\hline Weight & $8.4^{\mathrm{c}}$ & $11.9^{c}$ & $2.3^{\mathrm{d}}$ & 5.0 & 0.5 & 6.2 & 1.0 & 1.6 \\
\hline Weight ${ }^{2}$ & 0.0 & $11.9^{c}$ & $5.9^{c}$ & $10.9^{c}$ & 0.0 & 6.2 & 0.3 & 1.9 \\
\hline BMI & 0.0 & $11.9^{\mathrm{c}, \mathrm{d}}$ & 0.4 & $11.3^{\mathrm{c}}$ & $4.3^{\mathrm{c}, \mathrm{d}}$ & $10.5^{\mathrm{c}, \mathrm{d}}$ & 1.6 & 3.5 \\
\hline $\mathrm{BMI}^{2}$ & 0.0 & $11.9^{\mathrm{c}, d}$ & 0.2 & $11.5^{\mathrm{c}}$ & 0.1 & 10.6 & 0.3 & 3.8 \\
\hline Glucose & $20.4^{\mathrm{c}}$ & $32.3^{c}$ & $2.4^{\mathrm{d}}$ & $13.9^{c}$ & 0.0 & 10.6 & 0.0 & 3.8 \\
\hline Glucose $^{2}$ & 0.0 & $32.3^{\mathrm{c}}$ & 2.0 & $15.9^{c}$ & $5.0^{\mathrm{c}}$ & $15.6^{\mathrm{c}, \mathrm{d}}$ & 0.1 & 3.9 \\
\hline Glucose $^{3}$ & 0.3 & $32.6^{\mathrm{c}}$ & 0.3 & $16.2^{\mathrm{c}}$ & 0.0 & $15.6^{\mathrm{c}, \mathrm{d}}$ & $5.9^{\mathrm{c}, \mathrm{d}}$ & 9.8 \\
\hline Uric acid & $6.8^{\mathrm{c}}$ & $39.4^{\mathrm{c}}$ & $4.5^{\mathrm{c}, \mathrm{d}}$ & $20.7^{\mathrm{c}}$ & 1.2 & $16.8^{\mathrm{c}}$ & $1.5^{\mathrm{d}}$ & 11.3 \\
\hline Uric acid $^{2}$ & 0.4 & $39.8^{\mathrm{c}}$ & $0.0^{\mathrm{d}}$ & $20.7^{c}$ & 0.0 & 16.8 & 0.8 & 12.1 \\
\hline \multirow[t]{2}{*}{ Uric acid $^{3}$} & 0.1 & $39.9^{\mathrm{c}}$ & $3.3^{\mathrm{c}, \mathrm{d}}$ & $24.0^{\mathrm{c}}$ & 0.1 & 16.9 & 1.5 & 13.6 \\
\hline & \multicolumn{4}{|c|}{ VLDL-C } & \multicolumn{4}{|c|}{ LDL-C } \\
\hline \multirow{2}{*}{$\begin{array}{l}\text { Regression model } \\
\text { concomitants }^{\mathrm{b}}\end{array}$} & \multicolumn{2}{|c|}{ Females } & \multicolumn{2}{|c|}{ Males } & \multicolumn{2}{|c|}{ Females } & \multicolumn{2}{|c|}{ Males } \\
\hline & Partial $^{\mathrm{a}}$ & Total $^{\mathrm{a}}$ & Partial & Total & Partial & Total & Partial & Total \\
\hline Age & 1.0 & 1.0 & 0.2 & 0.2 & 2.0 & 2.0 & 0.0 & 0.0 \\
\hline Height & 0.7 & 1.7 & 0.1 & 0.3 & 0.3 & 2.3 & 0.6 & 0.6 \\
\hline Height $^{2}$ & 0.0 & 1.7 & $3.5^{\mathrm{c}}$ & 3.8 & $4.1^{\mathrm{c}, \mathrm{d}}$ & $6.4^{\mathrm{c}, \mathrm{d}}$ & 0.4 & 1.0 \\
\hline Weight & $2.7^{\mathrm{e}}$ & 4.4 & $1.5^{\mathrm{e}}$ & 5.3 & 0.1 & 6.5 & 1.6 & 2.6 \\
\hline Weight $^{2}$ & 0.0 & 4.4 & $5.2^{c}$ & $10.5^{c}$ & 0.0 & 6.5 & 0.0 & 2.6 \\
\hline BMI & 0.8 & 5.2 & 0.1 & $10.6^{c}$ & $5.1^{\mathrm{c}}$ & $11.6^{\mathrm{c}, \mathrm{d}}$ & 1.6 & 4.2 \\
\hline $\mathrm{BMI}^{2}$ & 0.1 & 5.3 & 0.7 & $11.3^{\mathrm{c}}$ & 0.1 & $11.7^{\mathrm{c}, \mathrm{d}}$ & 0.0 & 4.2 \\
\hline Glucose & $10.1^{c, d}$ & $15.4^{\mathrm{c}, \mathrm{d}}$ & 0.5 & 11.8 & 0.3 & 12.0 & 0.2 & 4.4 \\
\hline Glucose ${ }^{2}$ & 0.0 & $15.4^{c, d}$ & $1.1^{\mathrm{e}}$ & $12.9^{\mathrm{d}}$ & $4.9^{\mathrm{c}, \mathrm{d}}$ & $16.9^{c, d}$ & 0.2 & 4.6 \\
\hline Glucose $^{3}$ & 0.3 & $15.7^{\mathrm{c}, \mathrm{d}}$ & 0.4 & 13.3 & 0.0 & $16.9^{\mathrm{c}, \mathrm{d}}$ & $7.8^{\mathrm{c}, \mathrm{d}}$ & 12.4 \\
\hline Uric acid & $4.8^{\mathrm{c}}$ & $20.5^{c, d}$ & $4.4^{\mathrm{c}, \mathrm{d}}$ & $17.7^{\mathrm{c}, \mathrm{d}}$ & 0.5 & $17.4^{\mathrm{c}, \mathrm{d}}$ & $4.4^{\circ}$ & 16.8 \\
\hline Uric acid $^{2}$ & 1.4 & $21.9^{c, d}$ & $1.1^{\mathrm{d}}$ & $18.8^{c}$ & 0.2 & $17.6^{\mathrm{c}, \mathrm{d}}$ & 0.1 & 16.9 \\
\hline \multirow[t]{2}{*}{ Uric acid $^{3}$} & 0.4 & $22.3^{c, d}$ & $3.8^{\mathrm{c}, \mathrm{d}}$ & $22.6^{c}$ & 0.0 & 17.6 & 2.4 & $19.3^{\mathrm{c}, \mathrm{d}}$ \\
\hline & \multicolumn{4}{|c|}{ HDL-C } & \multicolumn{4}{|c|}{ HDL2-C } \\
\hline \multirow{2}{*}{$\begin{array}{l}\text { Regression model } \\
\text { concomitants }^{\mathrm{b}}\end{array}$} & \multicolumn{2}{|c|}{ Females } & \multicolumn{2}{|c|}{ Males } & Fem & les & $\mathrm{Ma}$ & \\
\hline & Partial $^{\mathrm{a}}$ & Total $^{a}$ & Partial & Total & Partial & Total & Partial & Total \\
\hline Age & 1.3 & 1.3 & 1.2 & 1.2 & $3.4^{\mathrm{c}}$ & $3.4^{\mathrm{c}}$ & 0.6 & 0.6 \\
\hline Height & 1.2 & 2.5 & 0.0 & 1.2 & 1.0 & $4.4^{c, d}$ & 0.1 & 0.7 \\
\hline Height $^{2}$ & 0.6 & 3.1 & 0.5 & 1.7 & 0.2 & 4.6 & 0.6 & 1.3 \\
\hline Weight & $15.5^{\mathrm{c}}$ & $18.6^{\mathrm{c}}$ & $3.4^{\mathrm{c}}$ & 5.1 & $15.6^{\mathrm{c}}$ & $20.2^{c}$ & $4.1^{\mathrm{e}}$ & 5.4 \\
\hline Weight $^{2}$ & 0.3 & $18.9^{c}$ & 1.3 & 6.4 & 0.6 & $20.8^{\mathrm{c}}$ & 1.5 & 6.9 \\
\hline BMI & 0.7 & $19.6^{c}$ & 0.0 & 6.4 & 2.3 & $23.1^{c}$ & 0.0 & 6.9 \\
\hline $\mathrm{BMI}^{2}$ & 0.0 & $19.6^{c}$ & $5.2^{\mathrm{c}}$ & $11.6^{\mathrm{c}}$ & 0.0 & $23.1^{\mathrm{c}}$ & $6.2^{c}$ & $13.1^{\mathrm{c}}$ \\
\hline Glucose & $5.8^{\mathrm{c}, \mathrm{d}}$ & $25.4^{\mathrm{c}}$ & $3.6^{\mathrm{c}}$ & $15.2^{\mathrm{c}}$ & $5.9^{\mathrm{c}}$ & $29.0^{\mathrm{c}}$ & $3.5^{\mathrm{c}}$ & $16.6^{\mathrm{c}}$ \\
\hline Glucose $^{2}$ & 1.9 & $27.3^{\mathrm{c}}$ & $3.6^{\mathrm{c}, \mathrm{d}}$ & $18.8^{c}$ & 0.2 & $29.2^{c}$ & $3.6^{\mathrm{c}, \mathrm{d}}$ & $20.2^{c}$ \\
\hline Glucose $^{3}$ & 1.1 & $28.4^{c}$ & 0.6 & $19.4^{c}$ & 1.6 & $30.8^{c}$ & 1.0 & $21.2^{\mathrm{c}}$ \\
\hline Uric acid & 1.7 & $30.1^{c}$ & 0.7 & $20.1^{c}$ & 1.6 & $32.4^{\mathrm{c}}$ & 1.0 & $22.2^{\mathrm{c}}$ \\
\hline Uric acid ${ }^{2}$ & 0.6 & $30.7^{\mathrm{c}}$ & $0.2^{\mathrm{d}}$ & $20.3^{\mathrm{c}}$ & 0.1 & $32.5^{\mathfrak{c}}$ & $0.0^{\mathrm{d}}$ & $22.2^{c}$ \\
\hline${\text { Uric } \text { acid }^{3}}^{3}$ & 0.0 & $30.7^{c}$ & $7.3^{\mathrm{c}, \mathrm{d}}$ & $27.6^{c}$ & 0.1 & $32.6^{c}$ & $7.6^{\boldsymbol{c}, \mathrm{d}}$ & $29.8^{\mathrm{c}}$ \\
\hline
\end{tabular}


APPENDIX A. (Continued)

\begin{tabular}{|c|c|c|c|c|c|c|c|c|}
\hline \multirow{3}{*}{$\begin{array}{l}\text { Regression model } \\
\text { concomitants }^{b}\end{array}$} & \multicolumn{4}{|c|}{ HDL3-C } & \multicolumn{4}{|c|}{ Apo B } \\
\hline & \multicolumn{2}{|c|}{ Females } & \multicolumn{2}{|c|}{ Males } & \multicolumn{2}{|c|}{ Females } & \multicolumn{2}{|c|}{ Males } \\
\hline & Partial $^{a}$ & Total $^{\mathrm{a}}$ & Partial & Total & Partial & Total & Partial & Total \\
\hline Age & 0.4 & 0.4 & 2.1 & 2.1 & $2.6^{\mathrm{d}}$ & $2.6^{\mathrm{d}}$ & 0.1 & 0.1 \\
\hline Height & 0.7 & 1.1 & 0.5 & 2.6 & 0.1 & 2.7 & 0.3 & 0.4 \\
\hline Height $^{2}$ & 0.9 & 2.0 & 0.1 & 2.7 & 0.7 & 3.4 & 0.0 & 0.4 \\
\hline Weight & $4.5^{\mathrm{c}}$ & 6.5 & 0.3 & 3.0 & 1.6 & 5.0 & $4.7^{\mathrm{c}}$ & $5.1^{\mathrm{d}}$ \\
\hline Weight $^{2}$ & 0.0 & 6.5 & 0.2 & 3.2 & 0.1 & 5.1 & 1.0 & 6.1 \\
\hline BMI & 0.5 & 7.0 & 0.1 & 3.3 & $2.8^{\mathrm{c}, \mathrm{d}}$ & 7.9 & 1.6 & 7.8 \\
\hline $\mathrm{BMI}^{2}$ & 0.0 & 7.0 & 0.6 & 3.9 & 0.5 & 8.4 & 1.1 & 8.9 \\
\hline Glucose & 1.5 & 8.5 & 1.3 & 5.2 & $4.2^{c}$ & $12.6^{\mathrm{c}}$ & $1.3^{\mathrm{d}}$ & 10.2 \\
\hline Glucose & $5.6^{\mathrm{c}, \mathrm{d}}$ & 14.1 & 1.1 & 6.3 & $3.6^{\mathrm{c}, \mathrm{d}}$ & $16.2^{\mathrm{c}}$ & $1.7^{\mathrm{d}}$ & $11.9^{\mathrm{d}}$ \\
\hline Glucose $^{3}$ & 0.0 & 14.1 & 0.0 & 6.3 & 0.0 & $16.2^{\mathrm{c}}$ & $5.6^{\mathrm{c}, \mathrm{d}}$ & $17.5^{\mathrm{c}}$ \\
\hline Uric acid & 0.6 & 14.7 & 0.0 & 6.3 & 1.9 & $18.1^{c}$ & 0.0 & $17.5^{\mathrm{c}}$ \\
\hline Uric acid $^{2}$ & 1.3 & 16.0 & $3.0^{\mathrm{d}}$ & 9.3 & 0.0 & $18.1^{\mathrm{c}}$ & $0.1^{\mathrm{d}}$ & $17.6^{\mathrm{d}}$ \\
\hline \multirow[t]{2}{*}{ Uric acid $^{3}$} & 0.4 & 16.4 & 1.9 & 11.2 & 0.1 & $18.2^{\mathrm{c}}$ & $4.4^{\mathrm{c}, \mathrm{d}}$ & $22.0^{\mathrm{c}}$ \\
\hline & \multicolumn{4}{|c|}{ VLDL-B } & \multicolumn{4}{|c|}{ LDL-B } \\
\hline \multirow{2}{*}{$\begin{array}{l}\text { Regression model } \\
\text { concomitants }\end{array}$} & \multicolumn{2}{|c|}{ Females } & \multicolumn{2}{|c|}{ Males } & \multicolumn{2}{|c|}{ Females } & \multicolumn{2}{|c|}{ Males } \\
\hline & Partial $^{a}$ & Total $^{\mathrm{a}}$ & Partial & Total & Partial & Total & Partial & Total \\
\hline Age & $3.3^{c, d}$ & $3.3^{\mathrm{c}, \mathrm{d}}$ & 0.0 & 0.0 & 1.1 & 1.1 & 0.2 & 0.2 \\
\hline Height & 0.0 & 3.3 & 0.6 & 0.6 & 0.0 & 1.1 & 0.0 & 0.2 \\
\hline Height $^{2}$ & 1.0 & 4.3 & 0.9 & 1.5 & 1.8 & 2.9 & 0.2 & 0.4 \\
\hline Weight & $3.9^{c}$ & $8.2^{c, d}$ & $1.9^{\mathrm{d}}$ & 3.4 & 0.3 & 3.2 & $3.6^{\mathrm{c}}$ & 4.0 \\
\hline Weight $^{2}$ & 0.9 & $9.1^{c, d}$ & 1.5 & 4.9 & 0.0 & 3.2 & 0.3 & 4.3 \\
\hline BMI & 0.3 & 9.4 & 0.6 & 5.5 & 2.7 & 5.9 & 1.4 & 5.7 \\
\hline $\mathrm{BMI}^{2}$ & 0.2 & 9.6 & 1.5 & 7.0 & 1.0 & 6.9 & 0.4 & 6.1 \\
\hline Glucose & $11.2^{c}$ & $20.8^{c}$ & 0.1 & 7.1 & 0.9 & 7.8 & $1.6^{\mathrm{d}}$ & 7.7 \\
\hline Glucose ${ }^{2}$ & 0.0 & $20.8^{\mathrm{c}}$ & 0.3 & $\dddot{7.4}$ & $4.3^{c}$ & 12.1 & $1.7^{\mathrm{d}}$ & 9.4 \\
\hline Glucose $^{3}$ & 0.4 & $21.2^{\mathrm{c}}$ & 0.1 & 7.5 & 0.2 & 12.3 & $7.2^{\mathrm{c}, \mathrm{d}}$ & $16.6^{c, d}$ \\
\hline Uric acid & $4.7^{\mathrm{c}}$ & $25.9^{\mathrm{c}}$ & $8.2^{\mathrm{c}, \mathrm{d}}$ & 15.7 & 0.5 & 12.8 & 2.7 & $19.3^{c, d}$ \\
\hline Uric acid ${ }^{2}$ & 0.0 & $25.9^{c}$ & $0.1^{d}$ & 15.8 & 0.0 & 12.8 & 0.0 & $19.3^{c, d}$ \\
\hline Uric acid $^{3}$ & 1.0 & $26.9^{c}$ & $3.6^{\mathrm{c}, \mathrm{d}}$ & 19.4 & 0.0 & 12.8 & 2.4 & $21.7^{\mathrm{c}, \mathrm{d}}$ \\
\hline
\end{tabular}

${ }^{\text {a }}$ Partial: the percent sum of squares for the concomitant; total: the percent sum of squares for the model. ${ }^{\mathrm{b}}$ The concomitants are listed in the order in which they were added to the model; thus, the sum of squares is conditional on the concomitants already entered into the regression model.

${ }^{c}$ Statistically significant, $P$-value $\leq 0.05$.

${ }^{a}$ If significant becomes nonsignificant and if nonsignificant becomes significant when outliers are removed (data $\log _{\mathrm{e}}$-transformed and untransformed).

${ }^{e}$ If lipid trait $\log _{e}$-transformed, concomitant becomes statistically significant, $P$-value $\leq 0.05$ (all data and without outliers). 
APPENDIX B. Correlations Between Adjusted Plasma Lipid Traits:

$\epsilon 3 / 2$ (upper triangle) correlation/t-value/P-value*; $\epsilon 3 / 3$ (lower triangle) correlation/t-value $/ P$-value*

\begin{tabular}{|c|c|c|c|c|c|c|c|c|c|c|}
\hline & \multicolumn{10}{|c|}{ Females } \\
\hline & LDL-C & HDL2-C & HDL3-C & TG & VLDL-C & VLDL-B & LDL-B & $\mathrm{TC}$ & HDL-C & APO B \\
\hline \multirow[t]{3}{*}{ LDL-C } & & -0.1938 & -0.2746 & -0.2414 & -0.0327 & $-0.4881^{b}$ & 0.8719 & 0.7469 & -0.2552 & 0.7355 \\
\hline & & -0.71 & -1.03 & -0.90 & -0.12 & -2.02 & 6.42 & 4.05 & -0.95 & 3.91 \\
\hline & & 0.49 & 0.32 & 0.39 & 0.91 & 0.06 & $<0.01$ & $<0.01$ & 0.36 & $<0.01$ \\
\hline \multirow[t]{3}{*}{ HDL2-C } & -0.1232 & & 0.5517 & $-0.4174^{\mathrm{a}}$ & -0.3545 & -0.3541 & -0.2496 & -0.1297 & 0.9267 & -0.4502 \\
\hline & -1.13 & & 2.39 & -1.66 & -1.37 & -1.37 & -0.93 & -0.47 & 8.89 & -1.82 \\
\hline & 0.26 & & 0.03 & $0.12(0.05)$ & 0.19 & 0.20 & 0.37 & 0.64 & $<0.01$ & 0.09 \\
\hline \multirow[t]{3}{*}{ HDL3-C } & 0.4357 & 0.3040 & & -0.4291 & $-0.5039^{b}$ & -0.1350 & -0.3831 & -0.3464 & 0.8247 & -0.4987 \\
\hline & 4.41 & 2.91 & & -1.71 & -2.10 & -0.49 & -1.50 & -1.33 & 5.26 & -2.07 \\
\hline & $<0.01$ & $<0.01$ & & 0.11 & 0.06 & 0.63 & 0.16 & 0.21 & $<0.01$ & 0.06 \\
\hline \multirow[t]{3}{*}{ TG } & 0.2303 & $-0.4662^{\mathrm{a}}$ & -0.0341 & & 0.9235 & 0.8428 & -0.1566 & 0.3394 & -0.4764 & 0.2487 \\
\hline & 2.16 & -4.80 & -0.31 & & 8.68 & 5.64 & -0.57 & 1.30 & -1.95 & 0.93 \\
\hline & 0.03 & $<0.01$ & 0.76 & & $<0.01$ & $<0.01$ & 0.58 & 0.22 & 0.07 & 0.37 \\
\hline \multirow[t]{3}{*}{ VLDL-C } & 0.4139 & -0.4517 & -0.0084 & 0.8694 & & 0.7407 & 0.0364 & 0.5793 & -0.4674 & 0.4169 \\
\hline & 4.14 & -4.61 & -0.08 & 16.03 & & 3.98 & 0.13 & 2.56 & -1.91 & 1.65 \\
\hline & $<0.01$ & $<0.01$ & 0.94 & $<0.01$ & & $<0.01$ & 0.90 & 0.02 & $0.08(0.05)$ & 0.12 \\
\hline \multirow[t]{3}{*}{ VLDL-B } & 0.2553 & $-0.3475^{b}$ & 0.0183 & 0.6841 & 0.6976 & & $-0.4549^{b}$ & 0.0469 & -0.3010 & -0.0086 \\
\hline & 2.41 & -3.38 & 0.17 & 8.55 & 8.87 & & -1.84 & 0.17 & -1.14 & -0.03 \\
\hline & 0.02 & $<0.01(0.01)$ & 0.87 & $<0.01$ & $<0.01$ & & 0.09 & 0.87 & 0.28 & 0.98 \\
\hline \multirow[t]{3}{*}{ LDL-B } & 0.8695 & -0.2795 & 0.2377 & 0.3733 & 0.5342 & 0.2183 & & 0.6612 & -0.3419 & 0.8943 \\
\hline & 16.04 & -2.65 & 2.23 & 3.67 & 5.76 & 2.04 & & 3.18 & -1.31 & 7.21 \\
\hline & $<0.01$ & 0.01 & 0.03 & $<0.01$ & $<0.01$ & 0.04 & & 0.01 & 0.21 & $<0.01$ \\
\hline \multirow[t]{3}{*}{$\mathrm{TC}$} & 0.9655 & -0.0330 & 0.5172 & 0.3570 & 0.5497 & 0.3536 & 0.8452 & & -0.2441 & 0.7721 \\
\hline & 33.80 & -0.30 & 5.51 & 3.48 & 5.99 & 3.44 & 14.41 & & -0.91 & 4.38 \\
\hline & $<0.01$ & 0.76 & $<0.01$ & $<0.01$ & $<0.01$ & $<0.01$ & $<0.01$ & & 0.38 & $<0.01$ \\
\hline \multirow[t]{3}{*}{ HDL-C } & 0.1326 & 0.8750 & 0.7272 & -0.3532 & -0.3297 & -0.2411 & -0.0806 & 0.2391 & & -0.5300 \\
\hline & 1.22 & 16.47 & 9.65 & -3.44 & -3.18 & -2.26 & -0.74 & 2.24 & & -2.25 \\
\hline & 0.23 & $<0.01$ & $<0.01$ & $<0.01$ & $<0.01$ & $0.03(0.13)$ & 0.46 & 0.03 & & 0.04 \\
\hline \multirow[t]{3}{*}{ APO B } & 0.8486 & -0.3558 & 0.2151 & 0.5441 & 0.6910 & 0.5031 & 0.9531 & 0.8580 & -0.1471 & \\
\hline & 14.62 & -3.47 & 2.01 & 5.91 & 8.71 & 5.30 & 28.69 & 15.22 & -1.35 & \\
\hline & $<0.01$ & $<0.01$ & 0.05 & $<0.01$ & $<0.01$ & $<0.01$ & $<0.01$ & $<0.01$ & 0.18 & \\
\hline
\end{tabular}

E4/3 (lower triangle) correlation/t-value/ $P$-value*

\begin{tabular}{|c|c|c|c|c|c|c|c|c|c|c|}
\hline & \multicolumn{10}{|c|}{ Females } \\
\hline & LDL-C & HDL2-C & HDL3-C & TG & VLDL-C & VLDL-B & LDL-B & $\mathrm{TC}$ & HDL-C & APO B \\
\hline HDL2-C & $\begin{array}{c}-0.5737 \\
-2.80 \\
0.01\end{array}$ & & & & & & & & & \\
\hline \multirow[t]{3}{*}{ HDL3-C } & 0.2215 & 0.0872 & & & & & & & & \\
\hline & 0.91 & 0.35 & & & & & & & & \\
\hline & 0.38 & 0.73 & & & & & & & & \\
\hline \multirow[t]{3}{*}{ TG } & $0.2936^{\mathrm{a}}$ & -0.5739 & -0.0169 & & & & & & & \\
\hline & 1.23 & -2.80 & -0.07 & & & & & & & \\
\hline & $0.24(0.03)$ & 0.01 & 0.95 & & & & & & & \\
\hline \multirow[t]{3}{*}{ VLDL-C } & $0.1810^{\mathrm{a}}$ & -0.5539 & -0.0753 & 0.9482 & & & & & & \\
\hline & 0.74 & -2.66 & -0.30 & 11.94 & & & & & & \\
\hline & $0.47(0.16)$ & 0.02 & 0.77 & $<0.01$ & & & & & & \\
\hline \multirow[t]{3}{*}{ VLDL-B } & 0.1959 & $-0.5270^{b}$ & 0.1573 & $0.8051^{\mathrm{bb}}$ & 0.8853 & & & & & \\
\hline & 0.80 & -2.48 & 0.64 & 5.43 & 7.61 & & & & & \\
\hline & 0.44 & $0.02(0.19)$ & 0.53 & $<0.01(0.06)$ & $<0.01$ & & & & & \\
\hline \multirow[t]{3}{*}{ LDL-B } & 0.8353 & -0.5153 & 0.2565 & $0.2624^{\mathrm{a}}$ & 0.1107 & 0.0844 & & & & \\
\hline & 6.08 & -2.41 & 1.06 & 1.09 & 0.45 & 0.34 & & & & \\
\hline & $<0.01$ & 0.03 & 0.30 & $0.29(0.04)$ & 0.66 & 0.74 & & & & \\
\hline \multirow[t]{3}{*}{$\mathrm{TC}$} & 0.9341 & -0.5585 & 0.2932 & 0.5536 & 0.4658 & 0.4594 & 0.7621 & & & \\
\hline & 10.47 & -2.69 & 1.23 & 2.66 & 2.11 & 2.07 & 4.71 & & & \\
\hline & $<0.01$ & 0.02 & 0.24 & 0.02 & 0.05 & 0.06 & $<0.01$ & & & \\
\hline \multirow[t]{3}{*}{ HDL-C } & -0.4284 & 0.9260 & 0.4568 & -0.5189 & -0.5232 & -0.4110 & -0.3629 & -0.3877 & & \\
\hline & -1.90 & 9.81 & 2.05 & -2.43 & -2.46 & -1.80 & -1.56 & -1.68 & & \\
\hline & 0.08 & $<0.01$ & 0.06 & 0.03 & 0.03 & 0.09 & 0.14 & 0.11 & & \\
\hline \multirow[t]{3}{*}{ APO B } & 0.8092 & -0.6668 & 0.2894 & 0.5615 & 0.4624 & 0.4877 & 0.9110 & 0.8544 & -0.4858 & \\
\hline & 5.51 & -3.58 & 1.21 & 2.71 & 2.09 & 2.23 & 8.83 & 6.58 & -2.22 & \\
\hline & $<0.01$ & $<0.01$ & 0.24 & 0.02 & 0.05 & $0.04(0.18)$ & $<0.01$ & $<0.01$ & 0.04 & \\
\hline
\end{tabular}


APPENDIX B. (Continued)

$\epsilon 3 / 2$ (upper triangle) correlation/t-value $/ P$-value*; $\epsilon 3 / 3$ (lower triangle) correlation/t-value/ $P$-value*

\begin{tabular}{|c|c|c|c|c|c|c|c|c|c|c|}
\hline & \multicolumn{10}{|c|}{ Males } \\
\hline & LDL-C & HDL2-C & HDL3-C & TG & VLDL-C & VLDL-B & LDL-B & $\mathrm{TC}$ & HDL-C & APO B \\
\hline \multirow[t]{3}{*}{ LDL-C } & & -0.3671 & -0.1992 & 0.1358 & $0.2451^{\mathrm{a}}$ & 0.1900 & 0.7884 & 0.8918 & -0.4455 & 0.6995 \\
\hline & & -1.77 & -0.91 & 0.61 & 1.13 & 0.87 & 5.73 & 8.82 & -2.23 & 4.38 \\
\hline & & 0.09 & 0.37 & 0.55 & $0.27(0.06)$ & 0.40 & $<0.01$ & $<0.01$ & 0.04 & $<0.01$ \\
\hline \multirow[t]{3}{*}{ HDL2-C } & 0.1258 & & -0.1528 & $-0.4735^{a}$ & -0.3739 & -0.2371 & -0.6238 & -0.2258 & 0.8823 & -0.5971 \\
\hline & 1.07 & & -0.69 & -2.40 & -1.80 & -1.09 & -3.57 & -1.04 & 8.38 & -3.33 \\
\hline & 0.29 & & 0.50 & 0.03 & $0.09(0.02)$ & 0.29 & $<0.01$ & 0.31 & $<0.01$ & $<0.01$ \\
\hline \multirow[t]{3}{*}{ HDL3-C } & 0.2337 & 0.4729 & & 0.0796 & -0.1067 & -0.0808 & -0.1789 & -0.1257 & 0.3304 & -0.1631 \\
\hline & 2.03 & 4.52 & & 0.36 & -0.48 & -0.36 & -0.81 & -0.57 & 1.57 & -0.74 \\
\hline & 0.05 & $<0.01$ & & 0.72 & 0.64 & 0.72 & 0.43 & 0.58 & 0.13 & 0.47 \\
\hline \multirow[t]{3}{*}{ TG } & 0.2755 & $-0.2665^{\mathrm{a}}$ & -0.0033 & & 0.9068 & $0.7373^{\mathrm{b}}$ & 0.5521 & 0.4189 & -0.4143 & 0.7414 \\
\hline & 2.41 & -2.33 & -0.03 & & 9.62 & 4.88 & 2.96 & 2.06 & -2.04 & 4.94 \\
\hline & 0.02 & 0.02 & 0.98 & & $<0.01$ & $<0.01$ & 0.01 & 0.05 & 0.06 & $<0.01$ \\
\hline \multirow[t]{3}{*}{ VLDL-C } & 0.2676 & -0.3468 & -0.1203 & 0.8810 & & $0.8551^{\mathrm{b}}$ & $0.4915^{\mathrm{a}}$ & 0.5660 & -0.4080 & 0.7396 \\
\hline & 2.34 & -3.12 & -1.02 & 15.69 & & 7.38 & 2.52 & 3.07 & -2.00 & 4.91 \\
\hline & 0.02 & $<0.01$ & 0.31 & $<0.01$ & & $<0.01$ & 0.02 & 0.01 & 0.06 & $<0.01$ \\
\hline \multirow[t]{3}{*}{ VLDL-B } & 0.1961 & -0.1686 & 0.0156 & 0.8056 & $0.7806^{b}$ & & 0.3246 & 0.4935 & -0.2649 & 0.6642 \\
\hline & 1.69 & -1.44 & 0.13 & 11.46 & 10.52 & & 1.53 & 2.54 & -1.23 & 3.97 \\
\hline & 0.10 & 0.15 & 0.90 & $<0.01$ & $<0.01$ & & 0.14 & 0.02 & 0.23 & $<0.01$ \\
\hline \multirow[t]{3}{*}{ LDL-B } & 0.8967 & 0.0311 & 0.1811 & 0.4315 & 0.3973 & $0.3297^{\mathrm{b}}$ & & 0.7362 & -0.6810 & 0.9225 \\
\hline & 17.07 & 0.26 & 1.55 & 4.03 & 3.65 & 2.94 & & 4.86 & -4.16 & 10.68 \\
\hline & $<0.01$ & 0.79 & 0.13 & $<0.01$ & $<0.01$ & $<0.01(0.12)$ & & $<0.01$ & $<0.01$ & $<0.01$ \\
\hline \multirow[t]{3}{*}{$\mathrm{TC}$} & 0.9414 & 0.2605 & 0.3579 & 0.4521 & 0.4549 & 0.3793 & 0.8749 & & -0.2756 & 0.7826 \\
\hline & 23.52 & 2.27 & 3.23 & 4.27 & 4.30 & 3.45 & 15.22 & & -1.28 & 5.62 \\
\hline & $<0.01$ & 0.03 & $<0.01$ & $<0.01$ & $<0.01$ & $<0.01$ & $<0.01$ & & 0.21 & $<0.01$ \\
\hline \multirow[t]{3}{*}{ HDL-C } & 0.1819 & 0.9486 & 0.7276 & -0.2087 & -0.3133 & -0.1256 & -0.0893 & 0.3314 & & -0.6480 \\
\hline & 1.56 & 25.24 & 8.94 & -1.80 & -2.78 & -1.07 & -0.76 & 2.96 & & -3.80 \\
\hline & 0.12 & $<0.01$ & $<0.01$ & $0.08(0.02)$ & 0.01 & 0.29 & 0.45 & $<0.01$ & & $<0.01$ \\
\hline \multirow[t]{3}{*}{ APO B } & 0.7900 & -0.0468 & 0.1448 & 0.6606 & 0.6267 & 0.6602 & 0.9266 & 0.8443 & 0.0155 & \\
\hline & 10.86 & -0.40 & 1.23 & 7.41 & 6.78 & 7.41 & 20.76 & 13.28 & 0.13 & \\
\hline & $<0.01$ & 0.69 & 0.22 & $<0.01$ & $<0.01$ & $<0.01$ & $<0.01$ & $<0.01$ & 0.90 & \\
\hline
\end{tabular}

$\epsilon 4 / 3$ correlation/t-value/ $P$-value*

\begin{tabular}{|c|c|c|c|c|c|c|c|c|c|c|}
\hline & \multicolumn{10}{|c|}{ Males } \\
\hline & LDL-C & HDL2-C & HDL3-C & TG & VLDL-C & VLDL-B & LDL-B & $\mathrm{TC}$ & HDL-C & APO B \\
\hline HDL2-C & $\begin{array}{l}0.0760 \\
0.31 \\
0.76\end{array}$ & & & & & & & & & \\
\hline HDL3-C & $\begin{array}{l}-0.1064 \\
-0.43 \\
0.67\end{array}$ & $\begin{array}{l}0.7853 \\
5.07 \\
<0.01\end{array}$ & & & & & & & & \\
\hline TG & $\begin{array}{l}-0.0598 \\
-0.24 \\
0.81\end{array}$ & $\begin{array}{l}-0.1018 \\
-0.41 \\
0.69\end{array}$ & $\begin{array}{l}0.1350 \\
0.55 \\
0.59\end{array}$ & & & & & & & \\
\hline VLDL-C & $\begin{array}{l}-0.0559 \\
-0.22 \\
0.83\end{array}$ & $\begin{array}{l}-0.3012 \\
-1.26 \\
0.22\end{array}$ & $\begin{array}{l}-0.0783 \\
-0.31 \\
0.76\end{array}$ & $\begin{array}{l}0.9464 \\
11.72 \\
<0.01\end{array}$ & & & & & & \\
\hline VLDL-B & $\begin{array}{l}-0.0502 \\
-0.20 \\
0.84\end{array}$ & $\begin{array}{l}-0.2758^{\mathrm{a}} \\
-1.15 \\
0.27(0.11)\end{array}$ & $\begin{array}{l}-0.0157 \\
-0.06 \\
0.95\end{array}$ & $\begin{array}{l}0.8993^{b} \\
8.22 \\
<0.01\end{array}$ & $\begin{array}{l}0.9600 \\
13.71 \\
<0.01\end{array}$ & & & & & \\
\hline LDL-B & $\begin{array}{l}0.9309 \\
10.19 \\
<0.01\end{array}$ & $\begin{array}{l}0.0435 \\
0.17 \\
0.86\end{array}$ & $\begin{array}{l}-0.1803 \\
-0.73 \\
0.47\end{array}$ & $\begin{array}{l}0.0683 \\
0.27 \\
0.79\end{array}$ & $\begin{array}{l}0.0624 \\
0.25 \\
0.81\end{array}$ & $\begin{array}{l}-0.0070 \\
-0.03 \\
0.98\end{array}$ & & & & \\
\hline $\mathrm{TC}$ & $\begin{array}{l}0.8423 \\
6.25 \\
<0.01\end{array}$ & $\begin{array}{l}0.2852 \\
1.19 \\
0.25\end{array}$ & $\begin{array}{l}0.2032 \\
0.83 \\
0.42\end{array}$ & $\begin{array}{l}0.4009 \\
1.75 \\
0.10\end{array}$ & $\begin{array}{l}0.3506 \\
1.50 \\
0.15\end{array}$ & $\begin{array}{l}0.3501 \\
1.50 \\
0.15\end{array}$ & $\begin{array}{l}0.8233 \\
5.80 \\
<0.01\end{array}$ & & & \\
\hline HDL-C & $\begin{array}{l}0.0231 \\
0.09 \\
0.93\end{array}$ & $\begin{array}{l}\quad 0.9814 \\
20.44 \\
<0.01\end{array}$ & $\begin{array}{l}0.8896 \\
7.79 \\
<0.01\end{array}$ & $\begin{array}{l}-0.0332 \\
-0.13 \\
0.90\end{array}$ & $\begin{array}{l}-0.2465 \\
-1.02 \\
0.32\end{array}$ & $\begin{array}{l}-0.2084 \\
-0.85 \\
0.41\end{array}$ & $\begin{array}{l}-0.0238 \\
-0.10 \\
0.93\end{array}$ & $\begin{array}{l}0.2735 \\
1.14 \\
0.27\end{array}$ & & \\
\hline APO B & $\begin{aligned} & 0.6816 \\
& 3.73 \\
< & 0.01\end{aligned}$ & $\begin{array}{l}-0.1519 \\
-0.61 \\
0.55\end{array}$ & $\begin{array}{l}-0.1540 \\
-0.62 \\
0.54\end{array}$ & $\begin{aligned} & 0.6309 \\
& 3.25 \\
< & 0.01\end{aligned}$ & $\begin{array}{l}0.6676 \\
3.59 \\
<0.01\end{array}$ & $\begin{aligned} & 0.6399 \\
& 3.33 \\
< & 0.01\end{aligned}$ & $\begin{aligned} & 0.7638 \\
& 4.73 \\
< & 0.01\end{aligned}$ & $\begin{aligned} & 0.8549 \\
& 6.59 \\
< & 0.01\end{aligned}$ & $\begin{array}{l}-0.1599 \\
-0.65 \\
0.53\end{array}$ & \\
\hline
\end{tabular}

a The correlation was categorized in the next higher level in the figures (e.g., no line to thin line) when the trait(s) was log $\mathrm{e}_{\mathrm{e}}$-transformed before the adjustment.

${ }^{b}$ The correlation was categorized in the next lower level in the figures (e.g., thin line to no line) when the trait(s) was log $\log _{\mathrm{e}}$ transformed before the adjustment.

* If the inferences about a correlation changed when the trait(s) was $\log _{\mathrm{e}}$-transformed before the adjustment, the $P$-value for the correlation after transformation is given in parentheses. 
APPENDIX C. Correlation Differences Between Apo E Genotypes: $\epsilon 3 / 3-\epsilon 3 / 2$ (upper triangle) difference/ $\chi^{2}$-value/P-value*; $\epsilon 3 / 3-\epsilon 4 / 3$ (lower triangle) difference/ $\chi^{2}$-value $/ P$-value ${ }^{*}$

\begin{tabular}{|c|c|c|c|c|c|c|c|c|c|c|}
\hline & \multicolumn{10}{|c|}{ Females } \\
\hline & LDL-C & HDL2-C & HDL3-C & TG & VLDL-C & VLDL-B & LDL-B & TC & HDL-C & APO B \\
\hline \multirow{3}{*}{ LDL-C } & & 0.0706 & 0.7103 & 0.4717 & 0.4466 & $0.7434^{\mathrm{bb}}$ & -0.0024 & 0.2186 & 0.3878 & 0.1131 \\
\hline & & 0.04 & 6.28 & 2.54 & 2.60 & 6.83 & 0.05 & 14.51 & 1.68 & 1.56 \\
\hline & & 0.84 & 0.01 & 0.11 & 0.11 & $0.01(0.10)$ & 0.83 & $<0.01$ & 0.19 & 0.21 \\
\hline \multirow[t]{3}{*}{ HDL2-C } & 0.4505 & & -0.2477 & -0.0488 & -0.0972 & 0.0066 & -0.0299 & 0.0967 & -0.0517 & 0.0944 \\
\hline & 3.44 & & 0.86 & 0.09 & 0.22 & 0.00 & 0.03 & 0.09 & 0.44 & 0.08 \\
\hline & 0.06 & & 0.35 & 0.77 & 0.64 & 0.96 & 0.87 & 0.76 & 0.51 & 0.77 \\
\hline \multirow[t]{3}{*}{ HDL3-C } & 0.2142 & 0.2168 & & 0.3950 & 0.4955 & 0.1533 & 0.6208 & 0.8636 & -0.0975 & 0.7138 \\
\hline & 0.88 & 0.73 & & 1.85 & 3.09 & 0.25 & 4.53 & 9.76 & 0.40 & 6.31 \\
\hline & 0.35 & 0.39 & & 0.17 & 0.08 & 0.62 & 0.03 & $<0.01$ & 0.53 & 0.01 \\
\hline \multirow[t]{3}{*}{ TG } & -0.0633 & 0.1077 & -0.0172 & & -0.0541 & -0.1587 & $0.5299^{b}$ & 0.0176 & 0.1232 & 0.2954 \\
\hline & 0.04 & 0.19 & 0.00 & & 0.45 & 1.25 & 3.43 & 0.02 & 0.17 & 1.62 \\
\hline & 0.84 & 0.66 & 0.95 & & 0.50 & 0.26 & 0.06 & 0.89 & 0.68 & 0.20 \\
\hline \multirow[t]{3}{*}{ VLDL-C } & 0.2329 & 0.1022 & 0.0669 & -0.0788 & & -0.0431 & 0.4978 & -0.0296 & 0.1377 & 0.2741 \\
\hline & 0.98 & 0.16 & 0.06 & 2.30 & & 0.01 & 3.70 & 0.00 & 0.21 & 2.19 \\
\hline & 0.32 & 0.69 & 0.81 & 0.13 & & 0.90 & $0.05(0.06)$ & 0.99 & 0.65 & 0.14 \\
\hline \multirow[t]{3}{*}{ VLDL-B } & 0.0594 & 0.1795 & -0.1390 & -0.1210 & -0.1877 & & $0.6732^{\mathrm{b}}$ & 0.3067 & 0.0599 & 0.5117 \\
\hline & 0.07 & 0.53 & 0.24 & 0.71 & 3.15 & & 5.48 & 1.24 & 0.02 & 3.70 \\
\hline & 0.79 & 0.47 & 0.62 & 0.40 & 0.08 & & $0.02(0.25)$ & 0.27 & 0.87 & 0.05 \\
\hline \multirow[t]{3}{*}{ LDL-B } & 0.0342 & 0.2358 & -0.0188 & 0.1109 & 0.4235 & 0.1339 & & 0.1840 & 0.2613 & 0.0588 \\
\hline & 0.44 & 0.91 & 0.00 & 0.26 & 3.32 & 0.28 & & 2.82 & 0.76 & 2.94 \\
\hline & 0.51 & 0.34 & 0.98 & 0.61 & $0.07(0.17)$ & 0.60 & & 0.09 & 0.38 & 0.09 \\
\hline \multirow[t]{3}{*}{ TC } & 0.0314 & 0.5255 & 0.2240 & -0.1966 & 0.0839 & -0.1058 & 0.0831 & & 0.4832 & 0.0859 \\
\hline & 2.25 & 4.47 & 1.12 & 0.68 & 0.26 & 0.15 & 1.11 & & 2.68 & 1.19 \\
\hline & 0.13 & 0.03 & 0.29 & 0.41 & 0.61 & 0.70 & 0.29 & & 0.10 & 0.28 \\
\hline \multirow[t]{3}{*}{ HDL-C } & 0.5610 & -0.0510 & 0.2704 & 0.1657 & 0.1935 & 0.1699 & 0.2823 & 0.6268 & & 0.3829 \\
\hline & 4.49 & 0.59 & 2.83 & 0.44 & 0.62 & 0.40 & 1.10 & 5.55 & & 1.95 \\
\hline & 0.03 & 0.44 & 0.09 & 0.51 & 0.43 & 0.53 & 0.30 & 0.02 & & 0.16 \\
\hline \multirow[t]{3}{*}{ APO B } & 0.0394 & 0.3110 & -0.0743 & -0.0174 & 0.2286 & 0.0154 & 0.0421 & 0.0036 & 0.3387 & \\
\hline & 0.43 & 2.17 & 0.06 & 0.00 & 1.92 & 0.03 & 2.18 & 0.07 & 1.77 & \\
\hline & 0.51 & 0.14 & 0.81 & 0.99 & 0.17 & 0.87 & 0.14 & 0.80 & 0.18 & \\
\hline
\end{tabular}

$\epsilon 3 / 3-\epsilon 3 / 2$ (upper triangle) difference $/ \chi^{2}$-value $/ P$-value; $\epsilon 3 / 3-\epsilon 4 / 3$ (lower triangle) difference/ $\chi^{2}$-value/P-value*

\begin{tabular}{|c|c|c|c|c|c|c|c|c|c|c|}
\hline & \multicolumn{10}{|c|}{ Males } \\
\hline & LDL-C & HDL2-C & HDL3-C & TG & VLDL-C & VLDL-B & LDL-B & $\mathrm{TC}$ & HDL-C & APO B \\
\hline \multirow[t]{3}{*}{ LDL-C } & & 0.4929 & 0.4329 & 0.1397 & 0.0225 & 0.0061 & 0.1083 & 0.0496 & 0.6274 & 0.0905 \\
\hline & & 3.93 & 2.97 & 0.36 & 0.02 & 0.00 & 2.83 & 2.10 & 6.62 & 0.86 \\
\hline & & 0.05 & 0.09 & 0.55 & 0.90 & 0.96 & 0.09 & 0.15 & 0.01 & 0.35 \\
\hline \multirow[t]{3}{*}{ HDL2-C } & 0.0498 & & 0.6257 & 0.2070 & 0.0271 & 0.0685 & 0.6549 & 0.4863 & 0.0663 & 0.5503 \\
\hline & 0.04 & & 6.94 & 0.80 & 0.01 & 0.06 & 8.62 & 3.77 & 3.58 & 6.06 \\
\hline & 0.84 & & 0.01 & 0.37 & 0.94 & 0.80 & $<0.01$ & 0.05 & 0.06 & 0.01 \\
\hline \multirow[t]{3}{*}{ HDL3-C } & 0.3401 & -0.3124 & & -0.0829 & -0.0136 & 0.0964 & 0.3600 & 0.4836 & 0.3972 & 0.3079 \\
\hline & 1.55 & 3.36 & & 0.10 & 0.00 & 0.14 & 2.02 & 3.90 & 5.55 & 1.47 \\
\hline & 0.21 & 0.07 & & 0.75 & 0.94 & 0.71 & 0.15 & 0.05 & 0.02 & 0.23 \\
\hline \multirow[t]{3}{*}{ TG } & $0.3353^{a}$ & -0.1647 & -0.1383 & & -0.0258 & 0.0683 & -0.1206 & 0.0332 & 0.2056 & -0.0808 \\
\hline & 1.55 & 0.41 & 0.24 & & 0.11 & 0.64 & 0.31 & 0.05 & 0.73 & 0.26 \\
\hline & 0.21 & 0.52 & 0.63 & & 0.74 & 0.42 & 0.58 & 0.82 & 0.39 & 0.61 \\
\hline \multirow[t]{3}{*}{ VLDL-C } & $0.3235^{\mathrm{a}}$ & -0.0456 & -0.0420 & -0.0654 & & -0.0745 & -0.0942 & -0.1111 & 0.0947 & -0.1129 \\
\hline & 1.44 & 0.06 & 0.03 & 1.59 & & 0.56 & 0.16 & 0.27 & 0.14 & 0.53 \\
\hline & 0.23 & 0.81 & 0.87 & 0.21 & & 0.45 & 0.69 & 0.61 & 0.71 & 0.47 \\
\hline \multirow[t]{3}{*}{ VLDL-B } & 0.2463 & 0.1072 & 0.0313 & -0.0937 & -0.1794 & & 0.0051 & -0.1142 & 0.1393 & -0.0040 \\
\hline & 0.81 & 0.13 & 0.01 & 1.16 & 9.08 & & 0.00 & 0.24 & 0.29 & 0.01 \\
\hline & 0.37 & 0.71 & 0.91 & 0.28 & $<0.01(0.39)$ & & 0.95 & 0.62 & 0.59 & 0.94 \\
\hline \multirow[t]{3}{*}{ LDL-B } & -0.0342 & -0.0124 & 0.3614 & 0.3632 & $0.3349^{\mathrm{b}}$ & $0.3367^{\mathrm{b}}$ & & 0.1387 & 0.5917 & 0.0041 \\
\hline & 0.27 & 0.00 & 1.71 & 2.10 & 1.74 & 1.63 & & 3.10 & 8.08 & 0.09 \\
\hline & 0.60 & 0.97 & 0.19 & 0.15 & 0.19 & 0.20 & & 0.08 & $<0.01$ & 0.76 \\
\hline \multirow[t]{3}{*}{$\mathrm{TC}$} & 0.0991 & -0.0247 & 0.1547 & 0.0512 & 0.1043 & 0.0292 & 0.0516 & & 0.6070 & 0.0617 \\
\hline & 4.41 & 0.00 & 0.42 & 0.09 & 0.27 & 0.03 & 0.75 & & 6.03 & 0.75 \\
\hline & 0.04 & 0.96 & 0.52 & 0.77 & 0.61 & 0.85 & 0.39 & & 0.01 & 0.39 \\
\hline \multirow[t]{3}{*}{ HDL-C } & 0.1588 & -0.0328 & -0.1620 & -0.1755 & -0.0668 & 0.0828 & -0.0655 & 0.0579 & & 0.6635 \\
\hline & 0.35 & 2.44 & 2.58 & 0.43 & 0.09 & 0.08 & 0.06 & 0.08 & & 9.19 \\
\hline & 0.55 & 0.12 & 0.11 & 0.51 & 0.76 & 0.78 & 0.81 & 0.78 & & $<0.01$ \\
\hline \multirow[t]{3}{*}{$\mathrm{APO} B$} & 0.1084 & 0.1051 & 0.2988 & 0.0297 & -0.0409 & 0.0203 & 0.1628 & -0.0106 & 0.1754 & \\
\hline & 1.02 & 0.13 & 1.16 & 0.09 & 0.02 & 0.06 & 6.06 & 0.00 & 0.38 & \\
\hline & 0.31 & 0.72 & 0.28 & 0.76 & 0.90 & 0.80 & 0.01 & 0.96 & 0.54 & \\
\hline
\end{tabular}

${ }^{a}$ The correlation difference was categorized in the next higher level in the figures (e.g., no line to thin line) when the trait(s) was log ${ }_{\mathrm{e}}$-transformed before the adjustment.

${ }^{b}$ The correlation difference was categorized in the next lower level in the figures (e.g., thin line to no line) when the trait(s) was $\log _{e}$-transformed before the adjustment.

* If the inferences about a correlation difference changed when the trait(s) was $\log _{\mathrm{e}}$-transformed before the adjustment, the $P$-value for the correlation difference after transformation is given in parentheses. 